\title{
Gallium and Indium Complexes for Ring-Opening Polymerization of Cyclic Ethers, Esters and Carbonates
}

Samuel Dagorne, ${ }^{\mathrm{a}, *}$ Mickael Normand, ${ }^{\mathrm{b}}$ Evgeny Kirillov, ${ }^{\mathrm{b}}$ and Jean-François Carpentier ${ }^{\mathrm{b}, *}$

${ }^{a}$ Univ. Strasbourg, UMR CNRS 7177, Lab DECOMET, Institut de Chimie de Strasbourg, F67000 Strasbourg, France

${ }^{\mathrm{b}}$ Univ. Rennes 1, UMR CNRS 6226, Organometallics, Materials and Catalysis; Institut des Sciences Chimiques de Rennes, F-35042 Rennes, France

Corresponding authors: dagorne@ unistra.fr; jean-francois.carpentier@univ-rennes1.fr

\section{Contents}

1. Introduction

2. Gallium-based initiators/catalysts for the ROP of cyclic ethers, esters and carbonates: synthesis, characterization and catalytic performance

2.1. Gallium complexes for the ROP of cyclic ethers

2.2. Gallium complexes for the ROP of cyclic esters and carbonates

3. Indium-based Initiators/catalysts for ROP of cyclic esters

3.1. Synthesis of well-defined indium-based complexes for ROP of cyclic esters

3.1.1. Salt metathesis reactions

3.1.2. Protonolysis reactions

3.1.2.1. Amido complexes

3.1.2.2. Alkyl complexes 


\subsubsection{Aryloxy and alkoxy complexes}

3.2. Polymerization of cyclic esters using indium complexes

\subsubsection{Amido-indium precursors}

\subsubsection{Alkyl-indium precursors}

\subsubsection{Alkoxy-indium complexes}

3.2.4. Three-component initiating systems

4. Conclusions

5. Acknowledgements

6. References

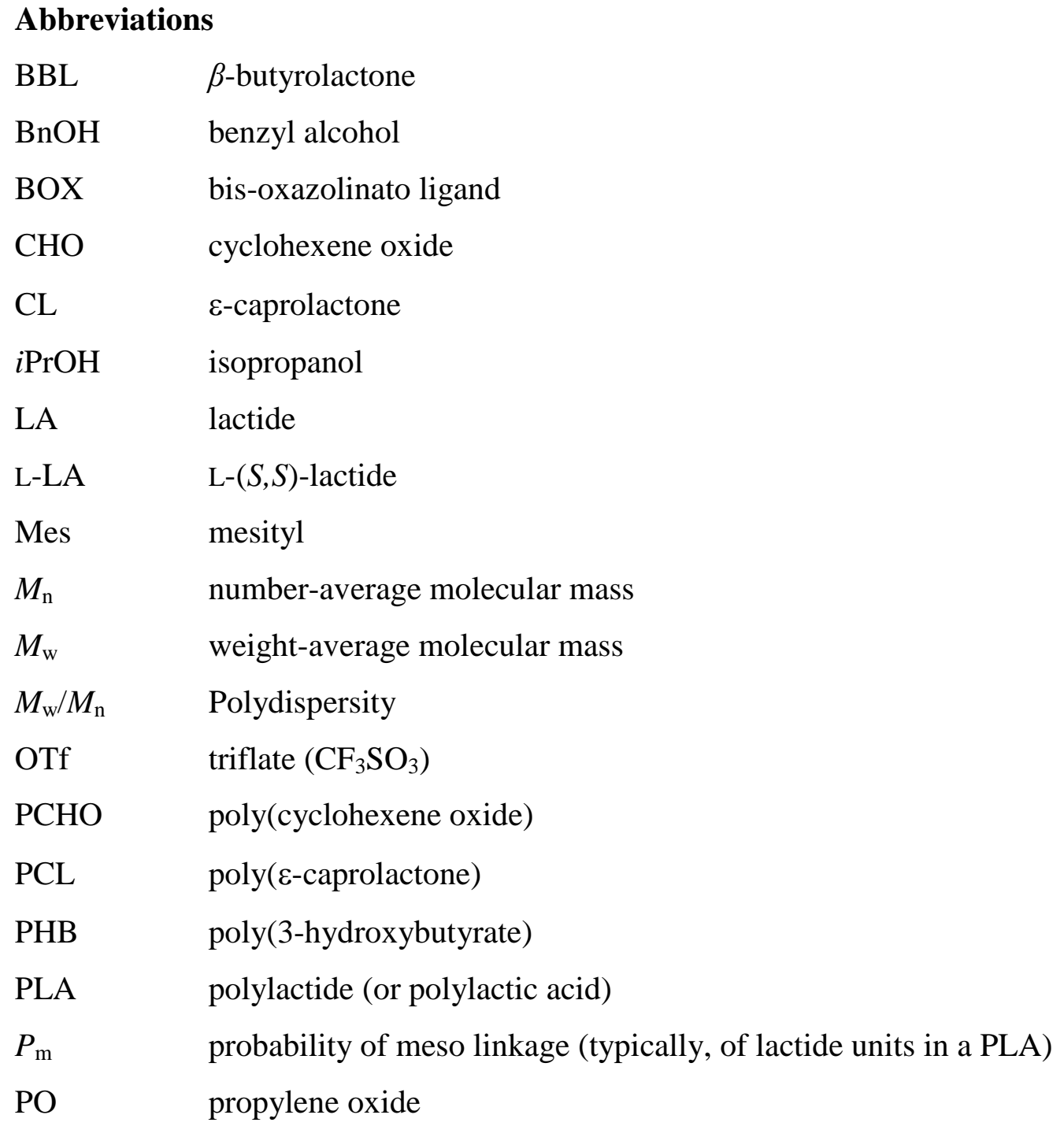




$\begin{array}{ll}\text { PPO } & \text { poly(propylene oxide) } \\ P_{\mathrm{r}} & \text { probability of racemic linkage (typically, of lactide units in a PLA) } \\ \text { PTMC } & \text { poly(trimethylene carbonate) } \\ \text { Rac } & \text { racemic } \\ \text { ROP } & \text { Ring-opening polymerization } \\ \text { SEC } & \text { Size-Exclusion Chromatography } \\ \text { SIMes } & \text { 1,3-bis(2,4,6-trimethylphenyl)imidazolin-2-ylidene } \\ \text { THF } & \text { tetrahydrofuran } \\ \text { TMC } & \text { trimethylene carbonate } \\ \text { TOF } & \text { TurnOver Frequency }\end{array}$

Highlights: Coordination chemistry of $\mathrm{Ga}(\mathrm{III})$ and $\mathrm{In}(\mathrm{III})$ to prepare well-defined chargeneutral, cationic and anionic complexes - Synthetic methodologies and structural features of such compounds - Use of those discrete complexes as initiators/catalysts in ring-opening polymerization of cyclic esters and ethers - Catalytic performances, structure/reactivity relationships and operative ROP mechanisms described and contrasted with those of their $\mathrm{Al}(\mathrm{III})$ analogues.

\begin{abstract}
Over the past five years, $\mathrm{Ga}(\mathrm{III})$ and most notably $\mathrm{In}(\mathrm{III})$ precursors have attracted a growing interest for application in ROP catalysis of cyclic esters, primarily lactide, and may now be considered as potentially efficient ROP initiators of cyclic esters/carbonates. Despite their higher cost (vs. Al), Ga and In derivatives exhibit key attractive features including: i) Ga(III) and $\operatorname{In}(\mathrm{III})$ are biocompatible metal centers and ii) their precursors are typically more stable than organoaluminum species in polar media. The present contribution reviews discrete $\mathrm{Ga}(\mathrm{III})$ and $\mathrm{In}(\mathrm{III})$ compounds thus far developed as ROP initiators of cyclic esters/carbonates. The very few reports on Ga(III)-mediated ROPs of cyclic ethers are also included. In addition to the ROP performances of such species, the synthesis and structural characterization of
\end{abstract}


these initiators are also provided and thoroughly discussed with, whenever appropriate, the establishment of structure/reactivity relationships and mechanistic pathways. 


\section{Introduction}

The ring-opening polymerization (ROP) of cyclic esters/carbonates, such as lactide (LA), $\varepsilon$-caprolactone (CL) and trimethylene carbonate (TMC), by discrete organic/inorganic initiators has been intensively investigated over the past ten to fifteen years as this methodology is best suited for the production of biodegradable polyesters/polycarbonates (most notably polylactide, PLA) in a controlled and possibly stereocontrolled manner [1]. The growth of this field primarily arises from the interest in the resulting materials, which are currently used for various applications (including medical, food commodities and packaging applications) and considered as possible alternatives to petrochemically-based plastics [2]. In this area, well-defined and ligand-supported complexes of oxophilic and Lewis acidic metals $(\mathrm{M}=\mathrm{Al}(\mathrm{III}), \mathrm{Sn}(\mathrm{II}), \mathrm{Zn}(\mathrm{II}), \mathrm{Mg}(\mathrm{II}), \mathrm{Ca}(\mathrm{II}), \mathrm{Ln}(\mathrm{III}), \mathrm{Ti}(\mathrm{IV}), \mathrm{Zr}(\mathrm{IV}))$ are efficient $\mathrm{ROP}$ initiators to access chain-length controlled and possibly stereoregular polyesters / polycarbonates via a controlled ROP process [1]. Among these, ligand-supported Al(III) alkoxide derivatives have been widely studied in polymerization catalysis of cyclic esters (primarily as lactide ROP initiators) as they typically allow a controlled ROP reaction and, most remarkably, may promote a high level of stereocontrol for the obtainment of highly stereoregular materials $[1,3]$. On that matter, reports on stereoselective ROP of rac-LA mediated by (salen)AlOR-type initiators for the production of PLA stereocomplexes constitute major contributions in the field $[1 \mathrm{k}, 4]$.

Over the past five years, in line with recent developments on the use and exploitation of non-conventional Lewis acids for the mediation of various organic reactions, lower group 13 metal precursors, i.e. $\mathrm{Ga}(\mathrm{III})$ and most notably $\mathrm{In}(\mathrm{III})$ derivatives, have witnessed a growing attention for application in ROP catalysis of cyclic esters, primarily lactide. Despite their higher cost (vs. Al), Ga and In derivatives benefit from two key attractive features: i) $\mathrm{Ga}(\mathrm{III})$ and $\mathrm{In}(\mathrm{III})$ are biocompatible metal centers and ii) their precursors are typically more 
stable than organoaluminum species in polar media. Though Ga(III) and In(III) compounds are typically thought to be less performant than their $\mathrm{Al}$ counterparts in polymerization catalysis due to their lower Lewis acidic character, such an assertion may be dampened by the now well-established peculiarities and advantages of $\mathrm{Ga}(\mathrm{III})$ and $\mathrm{In}(\mathrm{III})$ species (vs. Al(III) analogues) in organic transformations, reflecting certain unique properties and reactivity of these lower group $13 \mathrm{M}(\mathrm{III})$ species [5]. As detailed in the present contribution, Ga(III)-and In(III)-based compounds have now established themselves as potentially efficient ROP initiators of cyclic esters/carbonates susceptible, in some instances, to outperform their Al analogues.

In this paper, the synthesis, structural characterization and cyclic esters/carbonates ROP performances of discrete $\mathrm{Ga}(\mathrm{III})$ and $\mathrm{In}(\mathrm{III})$ compounds are comprehensively reviewed. The very few reports on Ga(III)-mediated ROPs of cyclic ethers are also discussed. A special emphasis is given on the synthetic methodologies and structural features of such compounds with, whenever appropriate, the establishment of structure/reactivity relationships. Also, when possible, the catalytic performances and operative ROP mechanisms of Ga(III) and In(III) compounds are contrasted with those of their $\mathrm{Al}(\mathrm{III})$ analogues.

\section{Gallium-based initiators/catalysts for the ROP of cyclic ethers, esters and carbonates:} synthesis, characterization and catalytic performance

\subsection{Gallium complexes for the ROP of cyclic ethers}

In 1992, Olah et al. first reported on the strong Lewis acid Ga(OTf) 3 being an effective catalyst for the bulk polymerization of THF at ambient temperature for the production of high-molecular-weight poly(THF) in excellent yield (Scheme 1) [6]. Such a Lewis-acidassisted ROP process likely proceeds via a cationic mechanism similar to that observed and 
studied by Atwood et al. in the ROP of propylene oxide initiated by salen-Al-type cationic species [7].

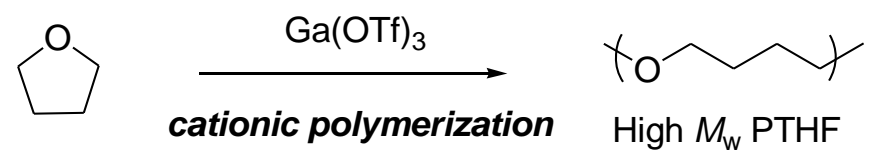

Scheme 1. Cationic polymerization of THF promoted by $\mathrm{Ga}(\mathrm{OTf})_{3}[6]$.

The molecular structure of the tris-THF Ga adduct $(\mathrm{OTf})_{3} \mathrm{Ga}(\mathrm{THF})_{3}(\mathbf{1})$, as recently Xray determined, features a central six-coordinate $\mathrm{Ga}$ metal center adopting a octahedral geometry with both the $\mathrm{TfO}^{-}$and THF ligands coordinating in a mer-fashion (Fig. 1) [8] The Ga- $\mathrm{O}_{\mathrm{THF}}$ bond distances in $\mathbf{1}(2.008(1) \AA$ in average $)$ are a bit shorter than, for instance, those observed in the cationic Ga moiety trans-Ga(acac $)_{2}(\mathrm{THF})^{+}[9]$, reflecting a fairly Lewis acidic $\mathrm{Ga}(\mathrm{III})$ center in $\mathbf{1}$.

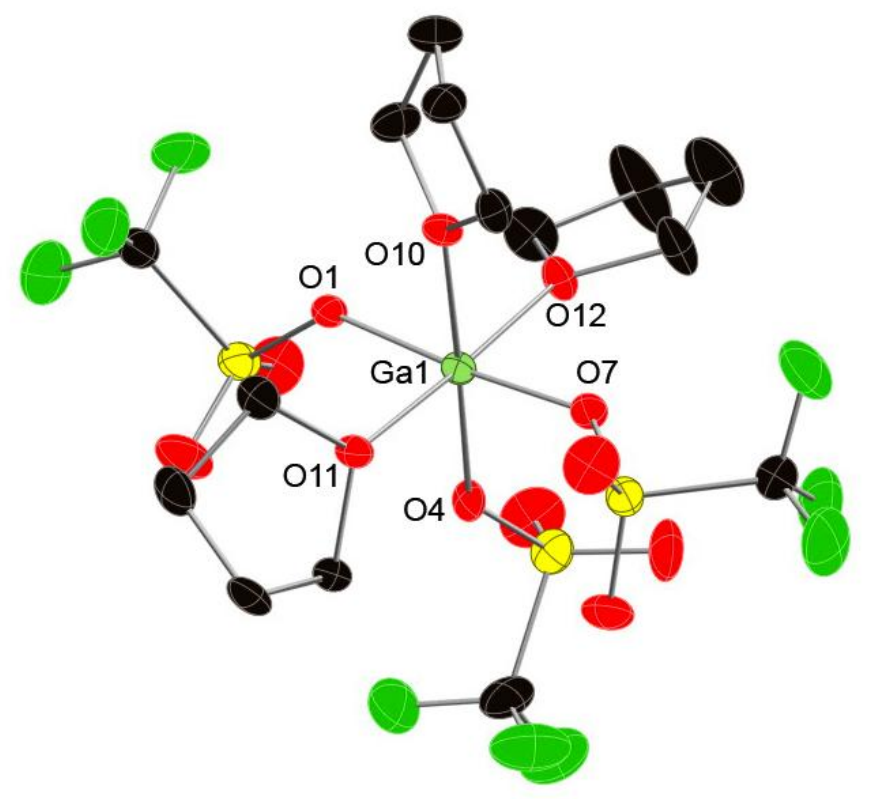


Fig. 1. Molecular structure of the tris-THF adduct $(\mathrm{TfO})_{3} \mathrm{Ga}(\mathrm{THF})_{3}(\mathbf{1})[8]$.

Albeit met with variable success, the preparation of discrete $\mathrm{Ga}(\mathrm{III})$ complexes supported by various multidentate nitrogen-based chelating ligands for subsequent use in propylene oxide (PO) polymerization has also been the subject of several reports. In the late 90 's, Bertrand et al. synthesized constrained group 13 complexes of the type $\eta^{3}-N, N^{\prime}, N^{\prime \prime}-$ $\left\{\left(\mathrm{RNCH}_{2} \mathrm{CH}_{2} \mathrm{CH}_{2}\right)_{2} \mathrm{NR}^{\prime}\right\} \mathrm{MX}\left(\mathrm{M}=\mathrm{Al}, \mathrm{Ga} ; \mathrm{R}, \mathrm{R}^{\prime}=\right.$ alkyl, silyl; $\mathrm{X}=\mathrm{Cl} ; \mathbf{2}$, Scheme 2) via a classical salt metathesis reaction between $\mathrm{MCl}_{3}$ and the amino-diamido dilithium salt of the pro-ligand [10]. Though some of the Al derivatives are active in PO oligomerization, no activity was observed for the Ga analogues, which was ascribed to the lower Lewis acidity when going from $\mathrm{Al}$ to $\mathrm{Ga}$.

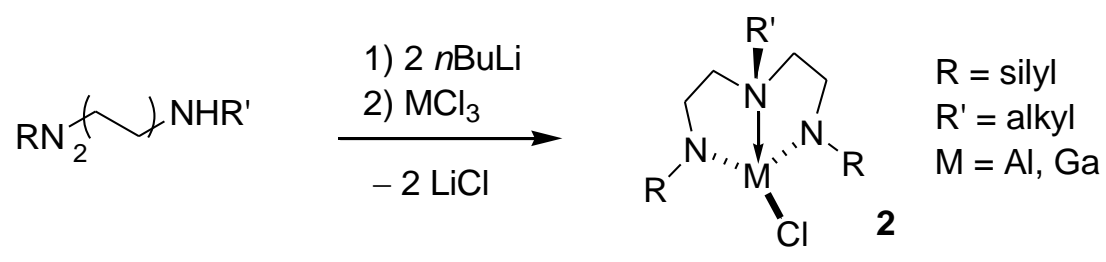

Scheme 2. A Amino-diamido\}-chloro gallium complexes explored in the polymerization of propylene oxide [10].

In contrast, as reported by Chisholm et al., the $\beta$-diketiminate $\mathrm{Ga}(\mathrm{III})$ triflate compound (NacNac)Ga(Cl)(OTf) (3, Scheme 3), accessible from ( $\mathrm{NacNac} \mathrm{GaCl}_{2}$ and AgOTf, readily mediates $\mathrm{PO}$ polymerization (neat $\mathrm{PO}$, room temperature), yet to yield highly regioirregular polypropylene oxide (PPO), typical of a Lewis-acid-assisted ROP of PO [11]. 


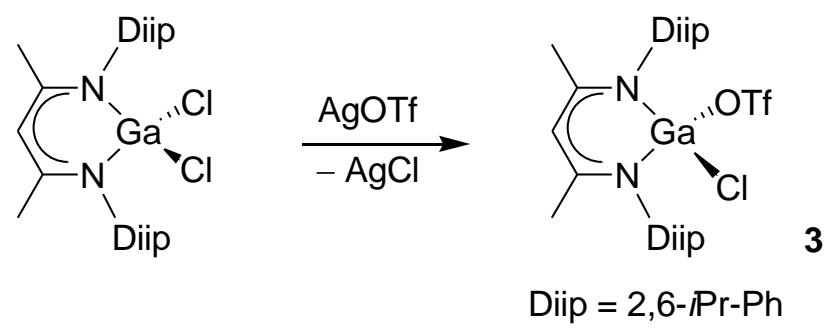

Scheme 3. $\beta$-Diketiminate $\mathrm{Ga}(\mathrm{III})$ complexes for the polymerization of propylene oxide [11].

In line with the apparent key role of Lewis acidity, well-defined cationic organogallium species stand as attractive candidates to promote the ROP of cyclic ethers. In a remarkable study, Wehmschulte et al. managed to isolate and characterize the first twocoordinate $\mathrm{Ga}$ organocation $\left[2,6-\mathrm{Mes}_{2} \mathrm{C}_{6} \mathrm{H}_{3}\right] \mathrm{Ga}^{+}\left(4\right.$, isolated as a $\mathrm{Li}\left[\mathrm{Al}\left\{\mathrm{OCH}\left(\mathrm{CF}_{3}\right)_{2}\right\}_{4}\right]_{2}^{-}$salt $)$ through a metathesis reaction of the neutral chloro precursor $\left[2,6-\mathrm{Mes}_{2} \mathrm{C}_{6} \mathrm{H}_{3}\right] \mathrm{GaCl}$ (Scheme 4) [12].

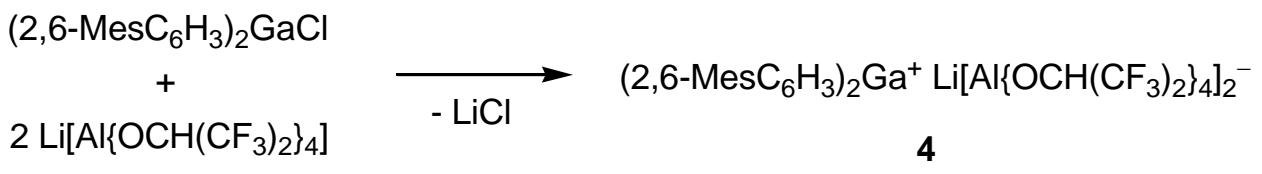

Scheme 4. Preparation of the two-coordinate Ga cation 4, used in the ROP of cyclohexene oxide [12]. 


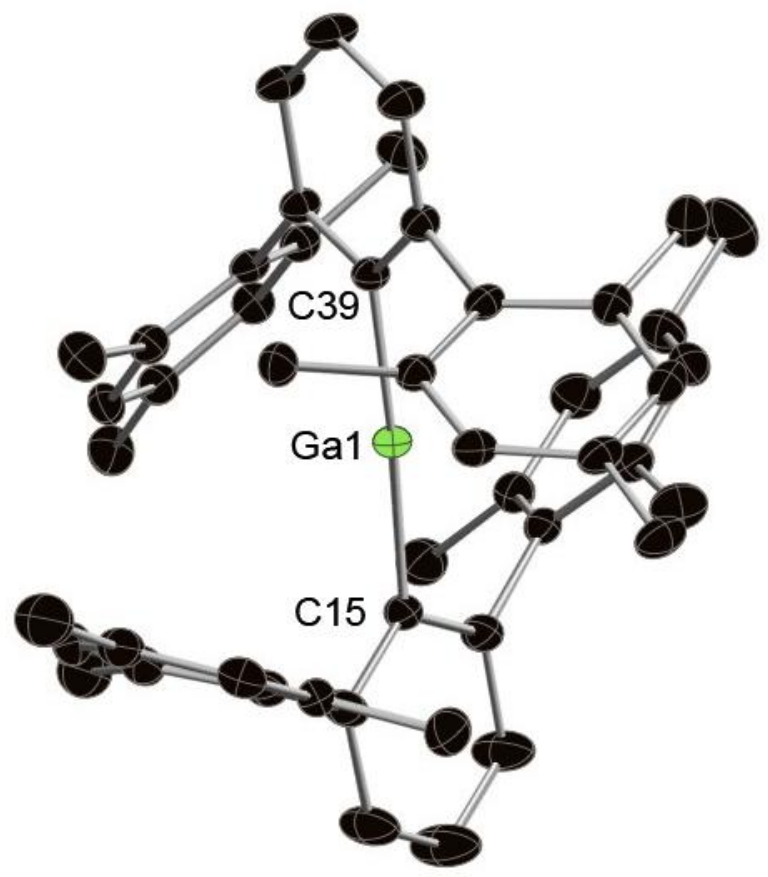

Fig. 2. Molecular structure of the two-coordinate Ga cation 4 [11]. The anion is omitted for clarity.

The highly Lewis acidic compound $\mathbf{4}$ is very active in the ROP of cyclohexene oxide ( $\mathrm{CHO}$, conditions: $\mathrm{C}_{6} \mathrm{H}_{5} \mathrm{Cl}$, room temperature) with an immediate consumption of the monomer within minutes to afford poly(cyclohexene oxide) (PCHO), which was not further characterized. As depicted in Fig. 2, cation 4 features a two-coordinate Ga center with an essentially linear $\mathrm{C}(15)-\mathrm{Ga}-\mathrm{C}(39)$ array $\left(175.69(7){ }^{\circ}\right)$ and enveloped by the bowl-shaped terphenyl substituents. The Ga-C bond distances (1.913(1) $\AA$ ) are extremely short for bonds of this type, which reflects their increased polar character along with the high electrophilicity of the $\mathrm{Ga}(\mathrm{III})$ center.

Three- and four-coordinate organogallium species supported by the monoanionic bisoxazolinato ligand BOX- $\mathrm{Me}_{2}{ }^{-},\left\{\mathrm{BOX}-\mathrm{Me}_{2}\right\} \mathrm{GaMe}^{+}$and $\left\{\mathrm{BOX}-\mathrm{Me}_{2}\right\} \mathrm{Ga}(\mathrm{Me})\left(\mathrm{NMe}_{2} \mathrm{Ph}\right)^{+}(\mathbf{5}$ and 6, respectively, Scheme 5) readily oligomerize PO (85\% conv. of 200 equiv of PO, room 
temperature, $15 \mathrm{~min}$. $)$ to afford low molecular weight PPO oligomers $\left(M_{\mathrm{n}}=339 \mathrm{~g} \cdot \mathrm{mol}^{-1}\right.$, $M_{\mathrm{w}} / M_{\mathrm{n}}=1.25$ ) [13]. Yet, the oligomerization process is clearly multimodal (as deduced from SEC data), with the probable involvement of several active species. While the threecoordinate $\mathrm{Ga}$ species $\mathbf{5}$ is thermally instable in solution at room temperature (as a $\mathrm{MeB}\left(\mathrm{C}_{6} \mathrm{~F}_{5}\right)_{3}{ }^{-}$salt $)$, the corresponding $\mathrm{Ga}-\mathrm{NMe}_{2} \mathrm{Ph}$ four-coordinate adduct 6 is fairly robust (Scheme 5).

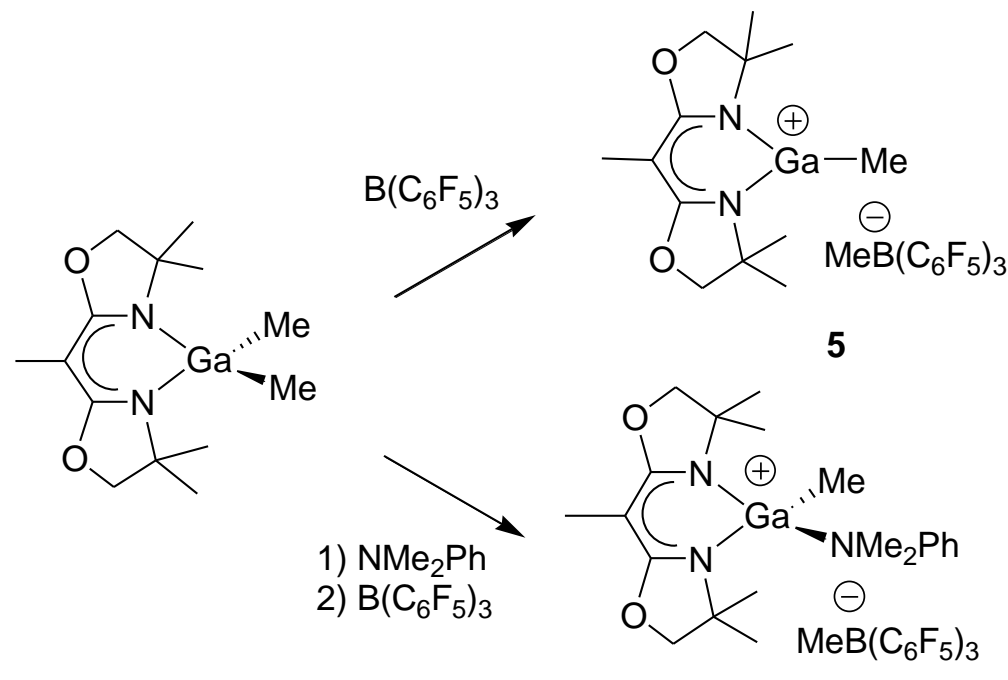

6

Scheme 5. Cationic bis(oxazolinato)-methylgallium complexes for the polymerization of propylene oxide [13].

As depicted in Fig. 3, the solid state molecular structure of $\mathbf{6}$ features a central fourcoordinate $\mathrm{Ga}(\mathrm{III})$ center effectively $\eta^{2}-N, N^{\prime}$-chelated by the $\mathrm{BOX}-\mathrm{Me}_{2}{ }^{-}$bidentate ligand, which results into the formation of a distorted six-membered ring $\mathrm{C}_{3} \mathrm{~N}_{2} \mathrm{Ga}$ metallacycle with the Ga center being displaced by $0.33(2) \AA$ from the $\mathrm{N}(2)-\mathrm{C}(6)-\mathrm{N}(1)-\mathrm{C}(9)$ average plane $[13]$. 


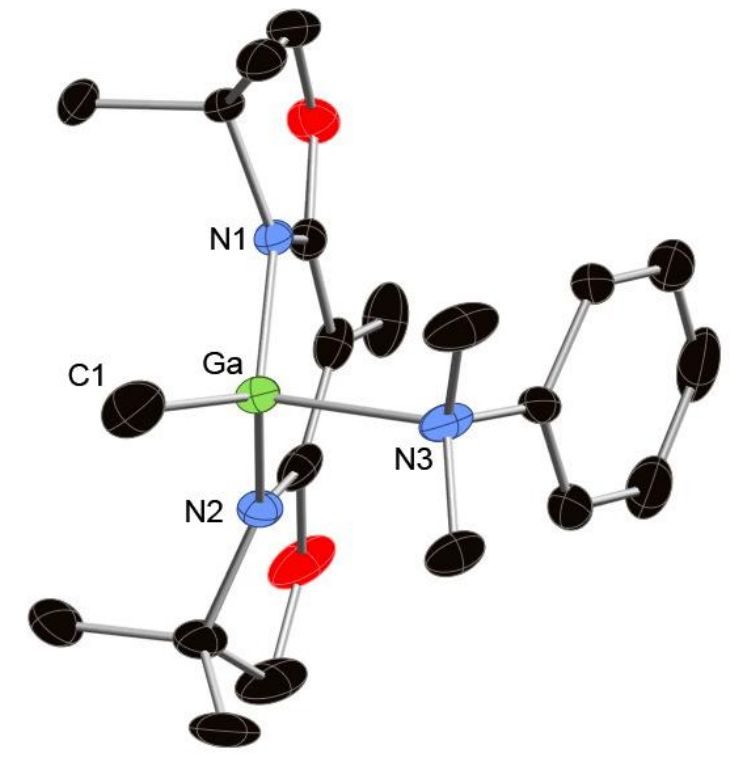

Fig. 3. Molecular structure of the four-coordinate Ga cation 6. The anion is omitted for clarity [13].

The potential utility of five-coordinate (salen) $\mathrm{GaX}$ species for the $\mathrm{CO}_{2} / \mathrm{CHO}$ copolymerization was also assessed by Darensbourg et al. Albeit inactive as co-polymerization initiators, the (salen) $\mathrm{GaCl}$ compounds $\mathbf{7 a}$ and $\mathbf{7 b}$ (Scheme 6) effectively homopolymerize $\mathrm{CHO}$ in the absence of any co-catalyst to yield PCHO, as deduced from NMR data [14]. In the solid state, the Ga initiators 7 exhibit bonding and structural parameters typical of group 13 salen species [15].

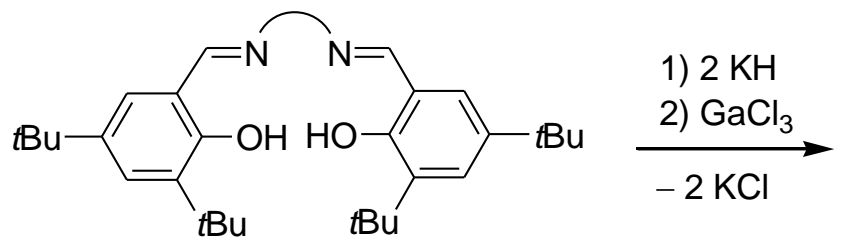<smiles></smiles>

$$
\frown \equiv \begin{aligned}
& \mathrm{CH}_{2}-\mathrm{CH}_{2}(7 \mathbf{a}) \\
& \text { cyclohexyl (7b) }
\end{aligned}
$$


Scheme 6. (Salen)GaX complexes for $\mathrm{CO}_{2} /$ cyclohexene oxide co-polymerization [14]

\subsection{Gallium complexes for the ROP of cyclic esters and carbonates}

The potential use of discrete Ga(III) compounds for use as ROP initiators of cyclic esters and carbonates has led to promising results over the past couple of years, which is likely to promote further investigations in the area. Thus, Horeglad et al. recently reported that the Ga alkoxide $(S)$-lactate complex $(S, S)-\left[\mathrm{Me}_{2} \mathrm{Ga}\left(\mu-\mathrm{OCH}(\mathrm{Me}) \mathrm{CO}_{2} \mathrm{Me}\right)\right]_{2}(\mathbf{8}$, scheme 7), accessible by alkane elimination reaction from $\mathrm{GaMe}_{3}$ and methyl $(S)$-lactate, effectively mediates the ROP of $r a c$-LA in a living manner to produce narrowly disperse atactic PLA (best run: 62\% conv. of 250 equiv of $r a c$-LA to PLA, $40^{\circ} \mathrm{C}, \mathrm{CH}_{2} \mathrm{Cl}_{2}, 48 \mathrm{~h}, M_{\mathrm{w}} / M_{\mathrm{n}}=1.1$ ) [16].

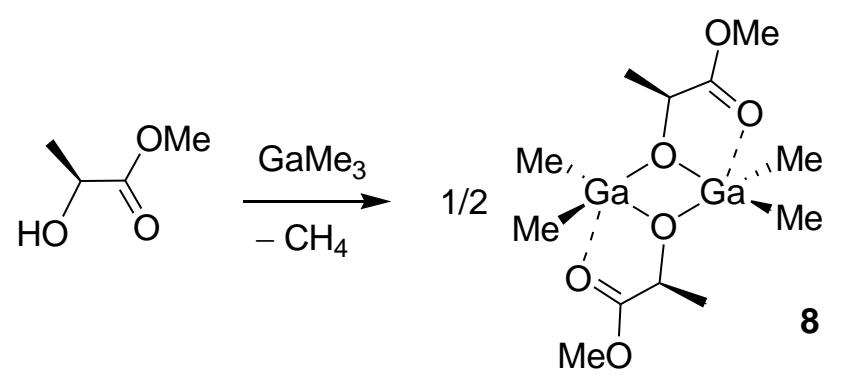

Scheme 7. Synthesis of $(S)$-lactate dimethylgallium complex for the ROP of rac-LA [16].

Remarkably, the addition of a Lewis base such as $\gamma$-picoline to compound 7 led to a stereoselective rac-LA ROP process to afford heterotactically-enriched PLA (probability of racemic linkage, $P_{\mathrm{r}}$, up to $78 \%$ ), thereby indicating that, in the present systems, the coordination of an external Lewis base to the Ga center is clearly beneficial. Various control experiments suggested a chain-end control polymerization process. Subsequent studies of this class of $\mathrm{Ga}(\mathrm{III})$ compounds but using an $N$-heterocyclic carbene (in the present case, SIMes) as an external Lewis base allowed the formation of the corresponding (SIMes)Ga alkoxide 
complexes 9a and 9b (Scheme 8) [17]. As deduced from the X-ray-determined solid state structure of $9 \mathbf{b}$ (Fig. 4), the strong coordination of the SIMes ligand to gallium causes a significant increase of the $\mathrm{NCN}$ angle $\left(108.6(1)^{\circ}\right)$, resulting in the stabilization of the monomer species.
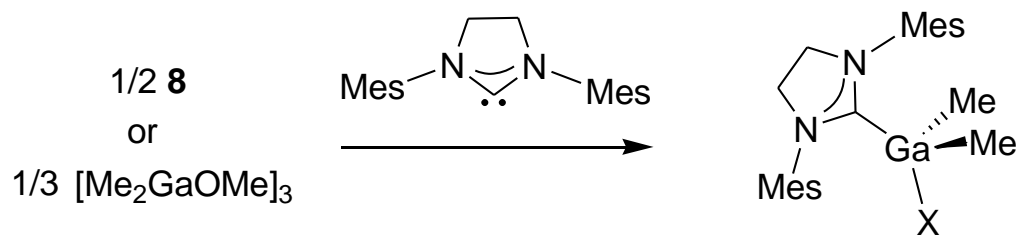

$9 a, X=(S)$-methyl lactate

$9 b, X=O M e$

Scheme 8. $N$-heterocyclic carbene (SIMes)Ga alkoxide complexes for the ROP of rac-LA [17].

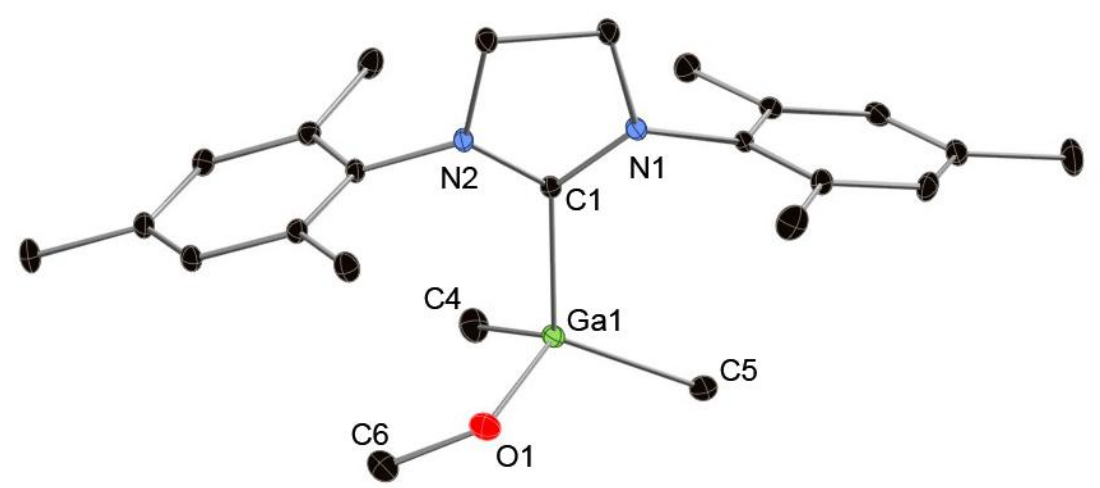

Fig. 4. Molecular structure of the $N$-heterocyclic carbene $\mathrm{Ga}$ complex (SIMes) $\mathrm{GaMe}_{2}(\mathrm{OMe})$ [17].

Interestingly, these NHC-Ga compounds exhibited a significantly higher polymerization rate (when compared to 7) in rac-LA ROP and were claimed to afford highly 
isotactic PLA (best run with 9a: quantitative conv. of 50 equiv of rac-LA to PLA, $-20{ }^{\circ} \mathrm{C}$, $\left.\mathrm{CH}_{2} \mathrm{Cl}_{2}, 30 \min . M_{\mathrm{w}} / M_{\mathrm{n}}=1.11, P_{\mathrm{m}}>0.99\right)$ [17]. The improved ROP activity of 9a,b was ascribed to an increased basicity of the Ga-OR moiety in $\mathbf{9 a}, \mathbf{b}$ along with, in the case of the Ga lactate derivative 9a, the absence of $\mathrm{C}=\mathrm{O}$ coordination to the fifth coordinate site of $\mathrm{Ga}(\mathrm{III})$. Thus, in these Ga-lactate systems, a stereoselectivity switch from a hetero- to an isoselectivity may be easily achieved upon changing the nature of the external Lewis base (going from $\gamma$-picoline to SIMes).

Tetracoordinate $\mathrm{Ga}(\mathrm{III})$ species of the type $(\mathrm{NON}) \mathrm{GaX}\left(\mathrm{X}=\mathrm{NMe}_{2}, \mathrm{Me} ; \mathbf{1 0}\right.$, Scheme 9), in which the $N, O, N$ diamido-ether dianionic ligand imposes a trigonal-monopyramidal geometry at the $\mathrm{Ga}(\mathrm{III})$ center for an increased reactivity, have very recently been developed by Dagorne et al. and subsequently tested as ROP initiators of cyclic esters (rac-LA and CL) and trimethylene carbonate (TMC) [18].
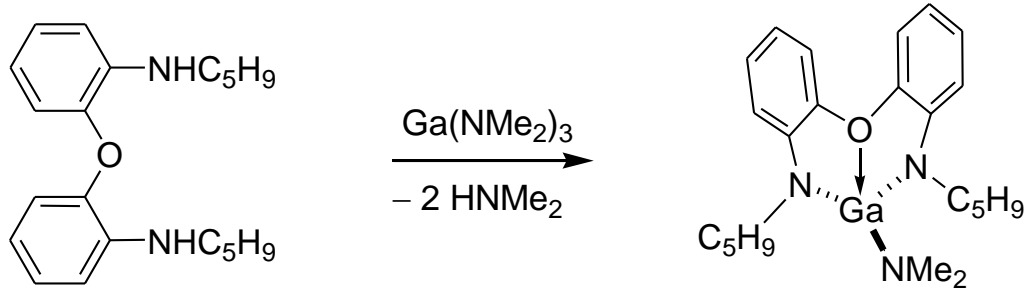

10
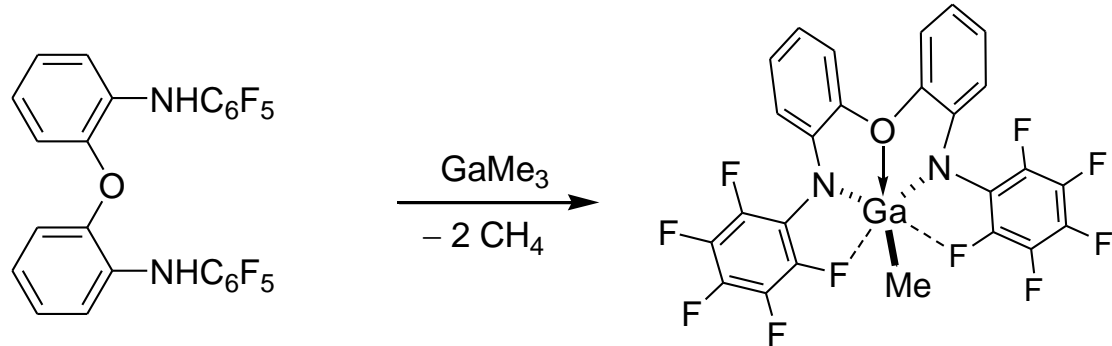

11

Scheme 9. Diamido gallium complexes for the ROP of cyclic esters [18]. 
The $N, O, N$-supported $\mathrm{Ga}$ amido $\eta^{3}-N, O, N-\left\{\left(\mathrm{C}_{5} \mathrm{H}_{9}\right) \mathrm{N}-\mathrm{C}_{6} \mathrm{H}_{4} \mathrm{O}\right\}_{2} \mathrm{GaNMe}_{2} \quad$ (10), synthesized via an amine elimination reaction of $\mathrm{Ga}\left(\mathrm{NMe}_{2}\right)_{3}$ with pro-ligand $\left\{\left(\mathrm{C}_{5} \mathrm{H}_{9}\right) \mathrm{NH}-\right.$ $\left.\mathrm{C}_{6} \mathrm{H}_{4}\right\}_{2} \mathrm{O}$, indeed features a $\mathrm{Ga}$ center adopting a tmp geometry with, in particular, the presence of an apical vacant site well-disposed for coordination to the Lewis acidic metal center (Fig. 5).

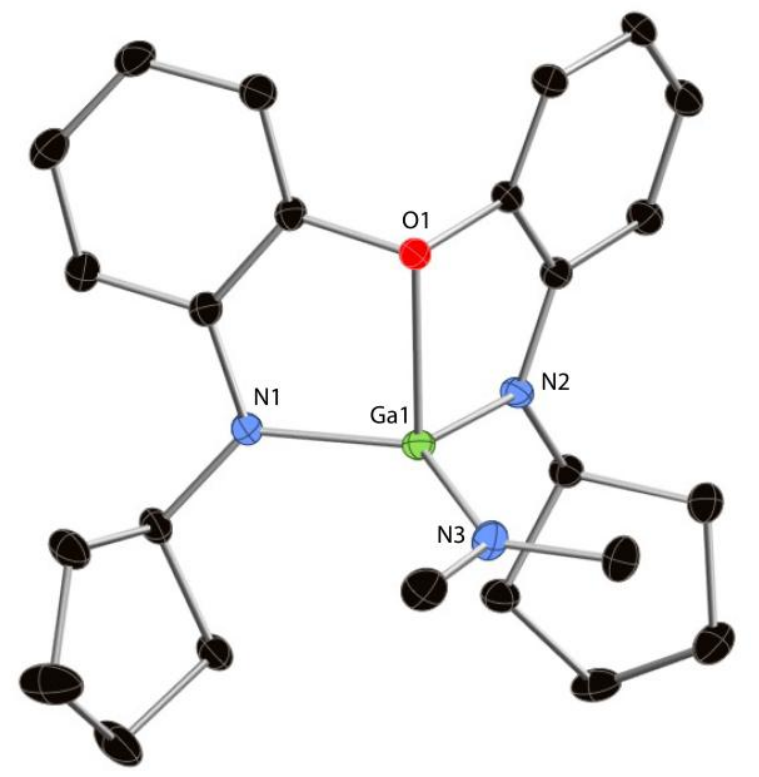

Fig. 5. Molecular structure of the Ga amido ROP initiator 10 [18].

Compound $\mathbf{1 0}$ initiates the controlled ROP of rac-LA under mild conditions to afford chain-length controlled PLA (best run with 10: quantitative conv. of 100 equiv of rac-LA to PLA, $80{ }^{\circ} \mathrm{C}$, toluene, $\left.1 \mathrm{~h}, M_{\mathrm{n}}=12390 \mathrm{~g} \cdot \mathrm{mol}^{-1}, M_{\mathrm{w}} / M_{\mathrm{n}}=1.11\right)$ [18]. Remarkably, the Ga species 10 clearly outperforms its $\mathrm{Al}$ analogue $\eta^{3}-N, O, N-\left\{\left(\mathrm{C}_{5} \mathrm{H}_{9}\right) \mathrm{N}_{-}-\mathrm{C}_{6} \mathrm{H}_{4} \mathrm{O}\right\}_{2} \mathrm{AlNMe}_{2}\left(\mathbf{1 0}^{\prime}\right)$ in the ROP of rac-LA whether regarding polymerization control and activity (for 10': $45 \%$ conv. of 100 equiv of rac-LA to PLA, $80{ }^{\circ} \mathrm{C}$, toluene, $\left.1 \mathrm{~h}, M_{\mathrm{n}}=14250 \mathrm{~g} \cdot \mathrm{mol}^{-1}, M_{\mathrm{w}} / M_{\mathrm{n}}=3.1\right)$. Carrying out the ROP of rac-LA using $\mathbf{1 0}$ in the presence an alcohol source such as benzyl 
alcohol $(\mathrm{BnOH})$ allowed the immortal ROP of $r a c$-LA to produce chain-length controlled and narrow disperse PLA chains, consistent with controlled alcohol-mediated chain transfer reactions during these Ga-mediated ROP reactions. Similarly, compound $\mathbf{1 0}$ efficiently promotes the immortal ROP of CL in a controlled manner to yield narrow disperse PCL. For instance, it was found that the initiating system $\mathbf{1 0} / \mathrm{BnOH}$ (in a $1: 5$ ratio) quantitatively polymerizes up to 600 equiv of $\mathrm{CL}$ within $3 \mathrm{~h}$ at room temperature in $\mathrm{CH}_{2} \mathrm{Cl}_{2}$ (for the resulting PCL: $\left.M_{\mathrm{n}}=12507 \mathrm{~g} \cdot \mathrm{mol}^{-1}, M_{\mathrm{w}} / M_{\mathrm{n}}=1.05\right)$. As for the ROP of TMC by species 10, it also proceeds smoothly at room temperature in the presence of $\mathrm{BnOH}$ via a fairly wellcontrolled immortal ROP process for the production of well-defined PTMC (typical run with 10: quantitative conv. of 100 equiv of TMC to PTMC, $\mathrm{CH}_{2} \mathrm{Cl}_{2}, 30 \mathrm{~min}, M_{\mathrm{n}}=2257 \mathrm{~g} \cdot \mathrm{mol}^{-1}$, $\left.M_{\mathrm{w}} / M_{\mathrm{n}}=1.15\right)$. Yet, as a comparison and unlike what is observed with rac-LA, the $\mathrm{Al}$ analogue 10' performs better than the Ga species 9 both in the ROP of CL and that of TMC, in line with the Lewis acidity of the metal center playing a determining role in group 13mediated ROPs of these two monomers. The lack of any ROP activity for the Ga complex $\eta^{3}$ $N, O, N-\left\{\left(\mathrm{C}_{6} \mathrm{~F}_{5}\right) \mathrm{N}-\mathrm{C}_{6} \mathrm{H}_{4}\right\}_{2} \mathrm{OGaMe}(\mathbf{1 1})$ most likely arises from the combination of steric factors and rather short $\mathrm{Ga} \cdots \mathrm{F}\left(o-\mathrm{C}_{6} \mathrm{~F}_{5}\right)$ contacts that severely limit monomer access to the $\mathrm{Ga}$ (III) center.

\section{Indium-based initiators/catalysts for ROP of cyclic esters}

In contrast to gallium derivatives, indium-based compounds have been almost exclusively used in the ROP of cyclic esters. A much larger variety of well-defined indium compounds exists though. Accordingly, the following sections address successively: i) the synthetic entries to discrete indium complexes that have found interesting ROP capabilities and ii) the catalytic performances of these compounds in ROP of cyclic esters. 


\subsection{Synthesis of well-defined indium-based complexes for ROP of cyclic esters}

\subsubsection{Salt metathesis reactions}

A particularly simple method for the preparation of well-defined indium complexes of potential utility in ROP is the salt metathesis of $\operatorname{In} X_{3}(X=\mathrm{Cl}, \mathrm{Br}, \mathrm{I})$ precursors with ligand alkali-metal (lithium or potassium) salts. However, this procedure sometimes leads to undesired or mixtures of compounds. The first indium-based complexes used for the ROP of a cyclic ester ( $\varepsilon$-caprolactone, CL) were described by Huang et al. and were prepared via such a route [19]. A salt metathesis reaction was conducted between $\mathrm{InCl}_{3}$ and 2 or 3 equiv of an amino-pyrrolate lithium salt, to afford the homoleptic complex $\mathbf{1 2}$ and the five-coordinated heteroleptic chloro- $(\mathbf{1 3})$, and eventually alkyl- $(\mathbf{1 4}, \mathbf{1 5})$ indium complexes in moderate to good yields (Scheme 10). The solid-state structure of the homoleptic complex 12 featured a five-coordinate indium center bearing one non-coordinated amino moiety. The solution ${ }^{1} \mathrm{H}$ NMR spectrum was consistent with a single species having three magnetically equivalent pyrrolyl ligands, certainly denoting rapid exchange of the amino moieties on the NMR time scale.

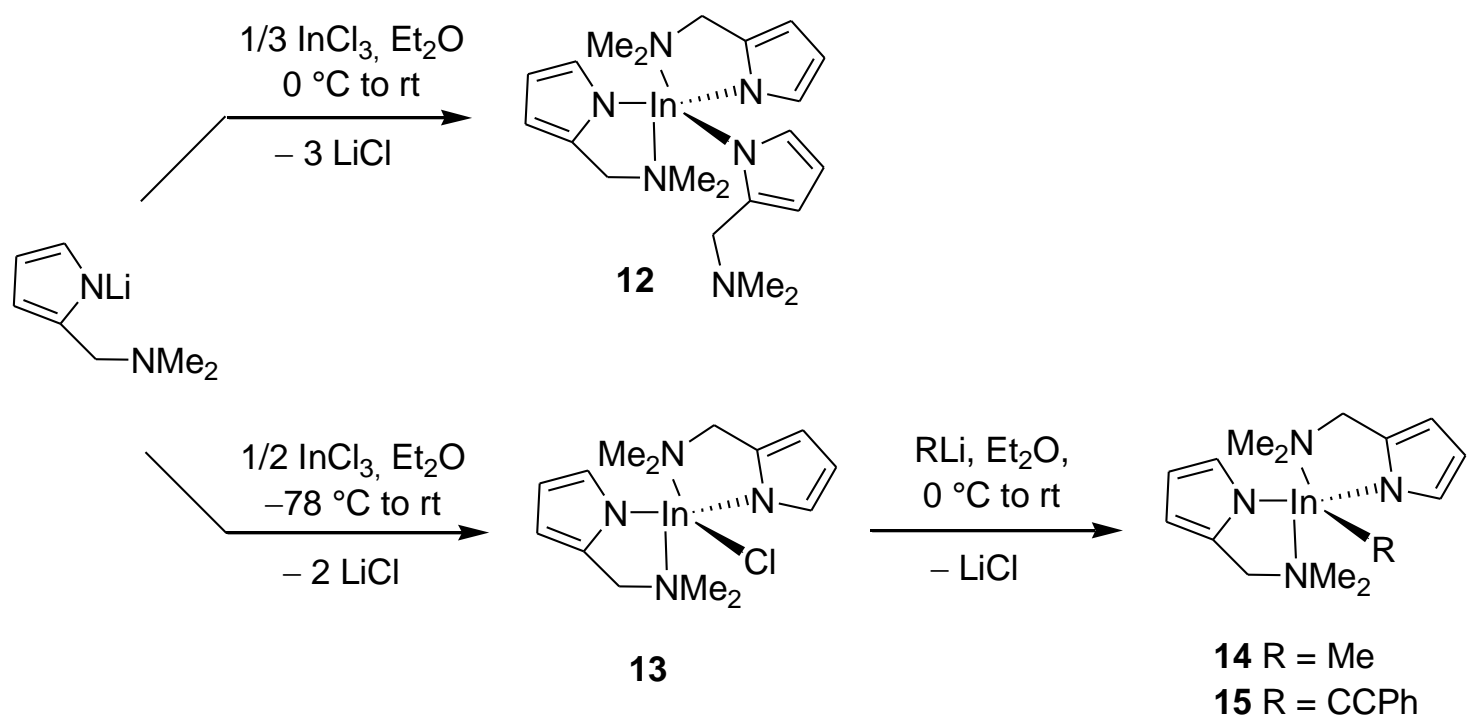


Scheme 10. Aminopyrrolyl indium complexes for the ROP of cyclic esters [19].

In 2008, Mehrkhodavandi et al. described a dinuclear halide/ethoxy-indium complex (19a, Fig. 6) bearing a chiral trans-1,2-diaminocyclohexenyl-phenoxy ligand [ 20 ], structurally related to that used by Tolman, Hillmyer and co-workers for zinc complexes [21]. A complete investigation of the structures of the mononuclear and dinuclear indium complexes, both in solution and in the solid state, was undertaken (Scheme 11) [22]. The choice of the solvent was essential for controlling of the nuclearity of the indium species. The mononuclear dihalide indium complexes 16a-e, 17a, 18a and 18e were obtained from the reaction of $\mathrm{InX}_{3}(\mathrm{X}=\mathrm{Cl}, \mathrm{Br}, \mathrm{I})$ and the corresponding phenolate ligands in toluene or THF. On the other hand, the two-step, one-pot reaction, carried out in diethylether, selectively yielded dinuclear halide/ethoxy- 19a-c, 19e, 20a, 21a and 22e along with the diethoxybridged indium complexes 22c, 23a and 23e as by-products. These diethoxy-bridged indium complexes are stable in polar (THF) and aliphatic (toluene) solvents and do not undergo any dissociation into mononuclear indium derivatives in the presence of an excess of alkali-ethoxy reactant. 


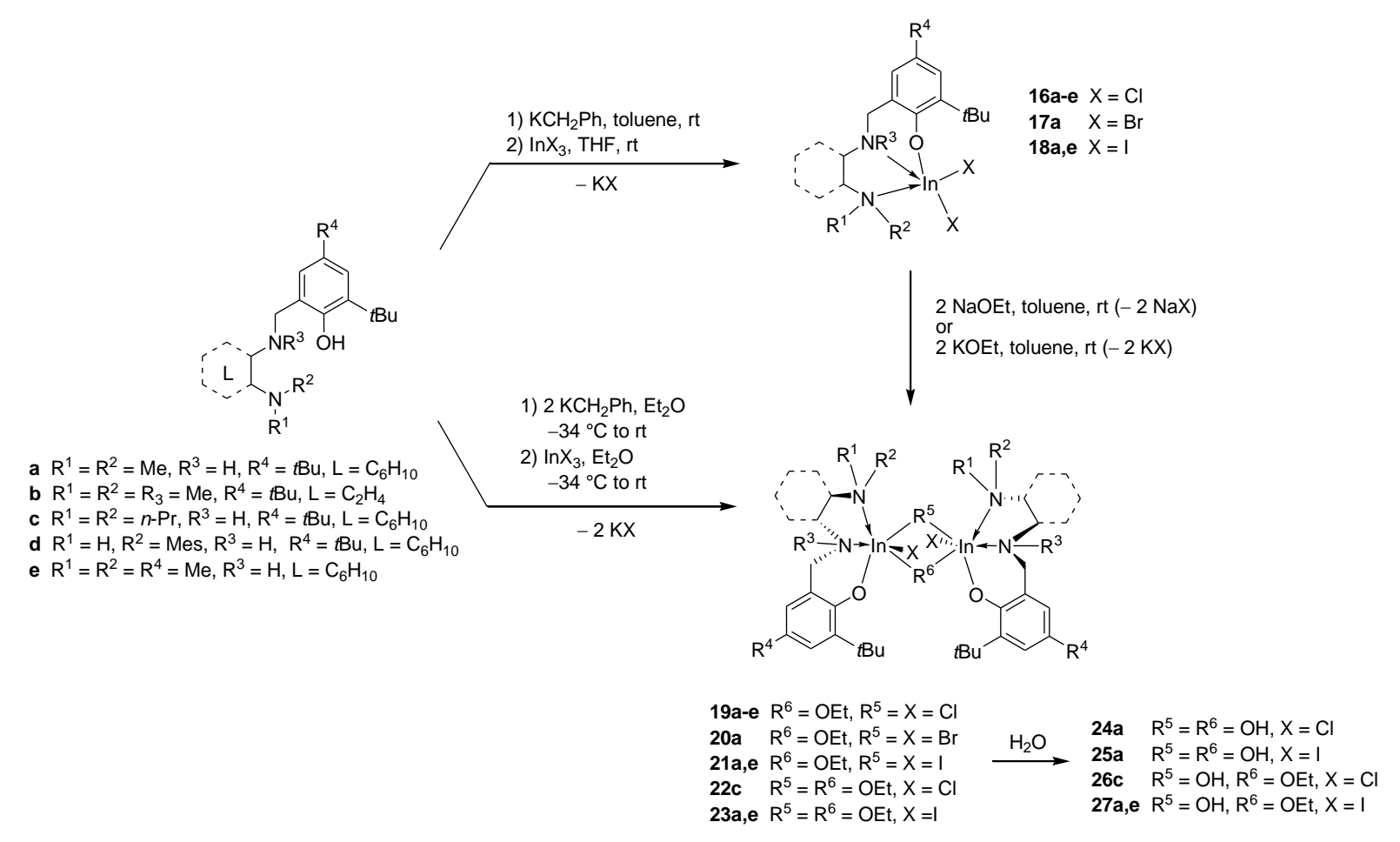

Scheme 11. Mono- and dinuclear indium complexes supported by diamino-phenoxy ligands developed by Mehrkhodavandi et al. for ROP of cyclic esters [20,22,23,24].

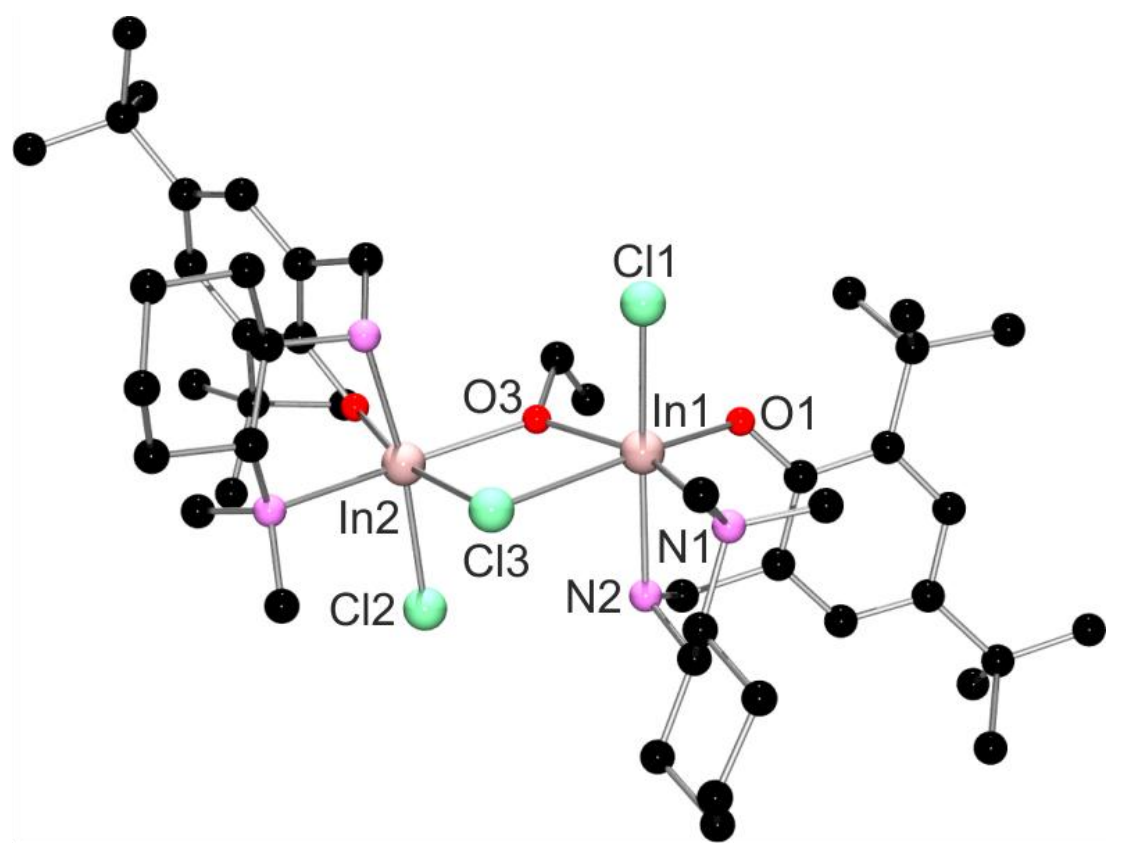

Fig. 6. Molecular structure of the halide/ethoxy-indium complex 19a [20]. 
Those dinuclear complexes reacted with water to form hydroxy-bridged species: i) halide/ethoxy-bridged indium complexes 19a and 21a yielded dihydroxy-bridged complexes 24a and 25a, respectively; ii) diethoxy-bridged indium derivatives 22c, 23a and 23e reacted with one equivalent of $\mathrm{H}_{2} \mathrm{O}$ to yield the hydroxy/ethoxy-bridged compounds 26c, 27a and 27e, respectively (Scheme 11) [20]. These hydroxy-bridged complexes do not dissociate either in THF or in toluene even at high temperature, but decompose to yield mixtures of species upon addition of 10 equiv of pyridine.

Okuda et al. reported the reaction between $\mathrm{InCl}_{3}$ and a dilithiated $\{\mathrm{OSSO}\}$-type dithiabisphenolate ligand to afford the mono-chloro-indium complex 30h (Scheme 12) [25]. The latter compound was assumed to be dimeric owing to its low solubility in non-polar solvents. Mountford et al. described the synthesis of amino-diamido complex 34a (Fig. 7) via the saltmetathesis reaction of the corresponding ligand sodium salt and $\mathrm{InCl}_{3}$ in THF [26]; due to the high insolubility of the resulting compound, it was isolated as a pyridine adduct after Soxhlet extraction in refluxing pyridine. Instead of the expected chloro-indium complex bearing a tetradentate $\left\{\mathrm{N}_{2} \mathrm{O}_{2}\right\}$-type bisphenolate ligand, Sun et al. isolated a water-bridged dinuclear chloro-indium complex 35 generated via a salt metathesis route (Fig. 8) [27]. 


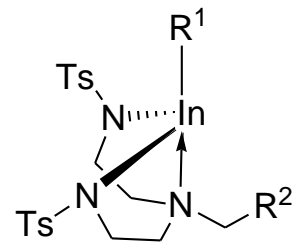

32a $\mathrm{R}^{1}=\mathrm{CH}_{2} \mathrm{SiMe}_{3}, \mathrm{R}^{2}=2$-pyridyl 32b $\mathrm{R}^{1}=\mathrm{CH}_{2} \mathrm{SiMe}_{3}, \mathrm{R}^{2}=\mathrm{CH}_{2} \mathrm{OMe}$ 32c $\mathrm{R}^{1}=\mathrm{CH}_{2} \mathrm{SiMe}_{3}, \mathrm{R}^{2}=\mathrm{Ph}$ 33a $R^{1}=\mathrm{N}\left(\mathrm{SiMe}_{3}\right)_{2}, R^{2}=2$-pyridyl 34a $R^{1}=C l, R^{2}=2$-pyridyl

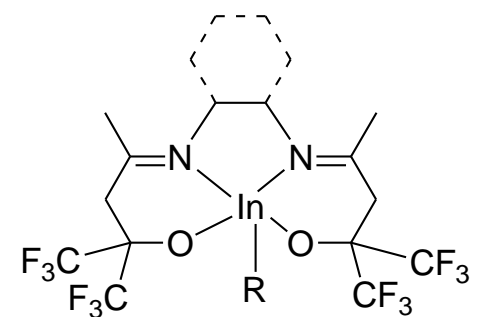

36a bridge: $\mathrm{C}_{2} \mathrm{H}_{4}, \mathrm{R}=\mathrm{Cl}$

37a bridge: $\mathrm{C}_{2} \mathrm{H}_{4}, \mathrm{R}=\mathrm{CH}_{2} \mathrm{SiMe}_{3}$

37b bridge: cyclo- $\mathrm{C}_{6} \mathrm{H}_{10}, \mathrm{R}=\mathrm{CH}_{2} \mathrm{SiMe}_{3}$

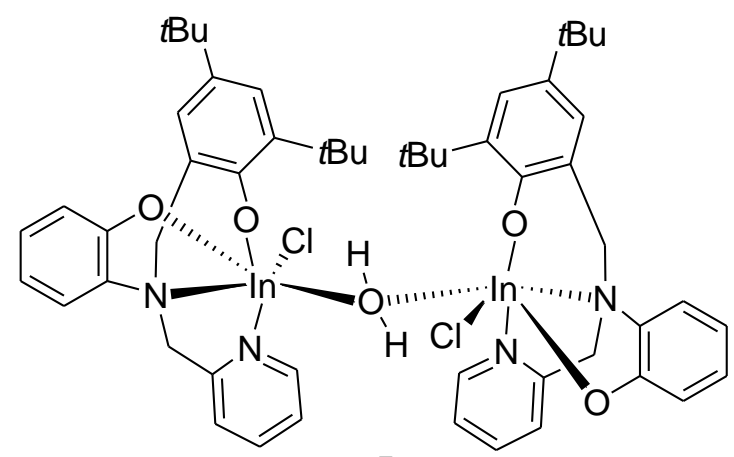

35

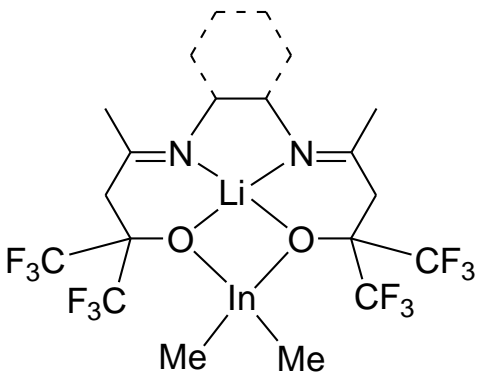

38a bridge: $\mathrm{C}_{2} \mathrm{H}_{4}$ 38b bridge: cyclo- $\mathrm{C}_{6} \mathrm{H}_{10}$

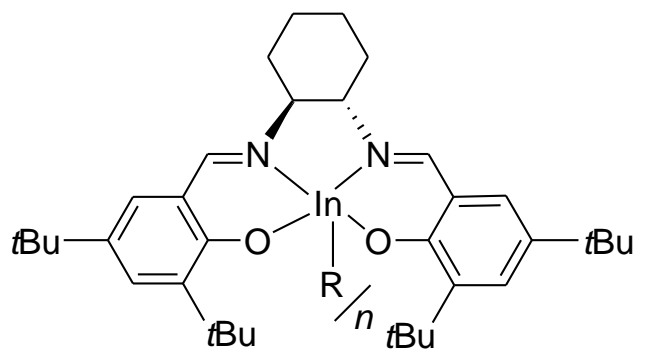

$39 \mathrm{R}=\mathrm{Cl}, n=1$

$40 \mathrm{R}=\mathrm{OEt}, n=2$

Fig. 7. Diverse chelating-ligand-supported indium complexes prepared for the ROP of racLA [26-28]. 


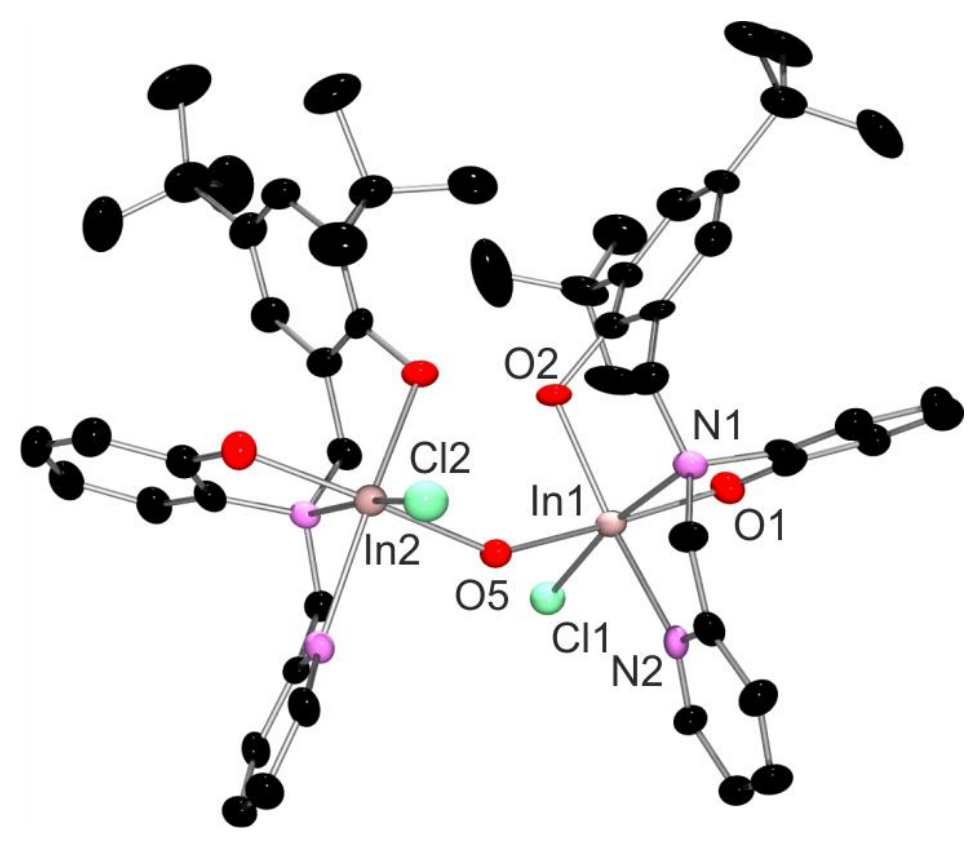

Fig. 8. Molecular structure of the water-brigded indium complex 35 [27].

Carpentier et al. reported the synthesis of a well-defined chloro-indium complex supported by a fluorinated diimino-dialkoxy ligand (36a; Fig. 7) [28]. The salt-metathesis reaction was selective only in the case of the ethylene-bridged ligand, as similar reactions attempted under identical conditions with the cyclohexylene-bridged diimino-dialkoxy ligand led to a mixture of unidentified products. More recently, Mehrkhodavandi et al. reported the successful preparation of a chiral chloro indium salen derivative (39; Fig. 7) using such a salt metathesis procedure from $\{$ Salen $\} K_{2}[29]$. 


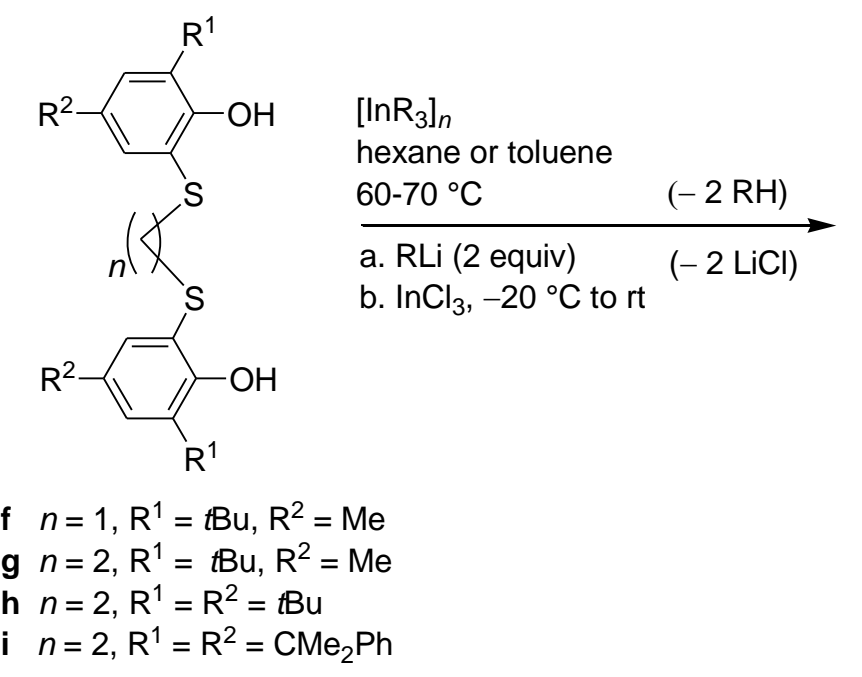

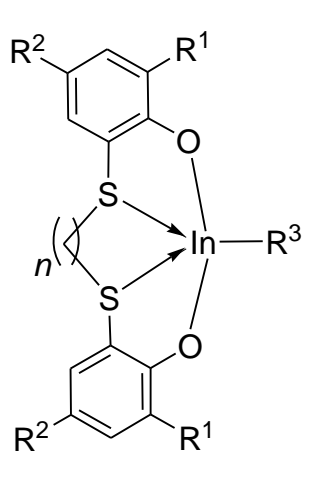

$$
\begin{array}{ll}
\text { 28f,g } \mathrm{R}^{3}=\mathrm{Me} \\
\text { 29h,i } \mathrm{R}^{3}=\mathrm{CH}_{2} \mathrm{SiMe}_{3} \\
\text { 30h } \mathrm{R}^{3}=\mathrm{Cl}
\end{array}
$$

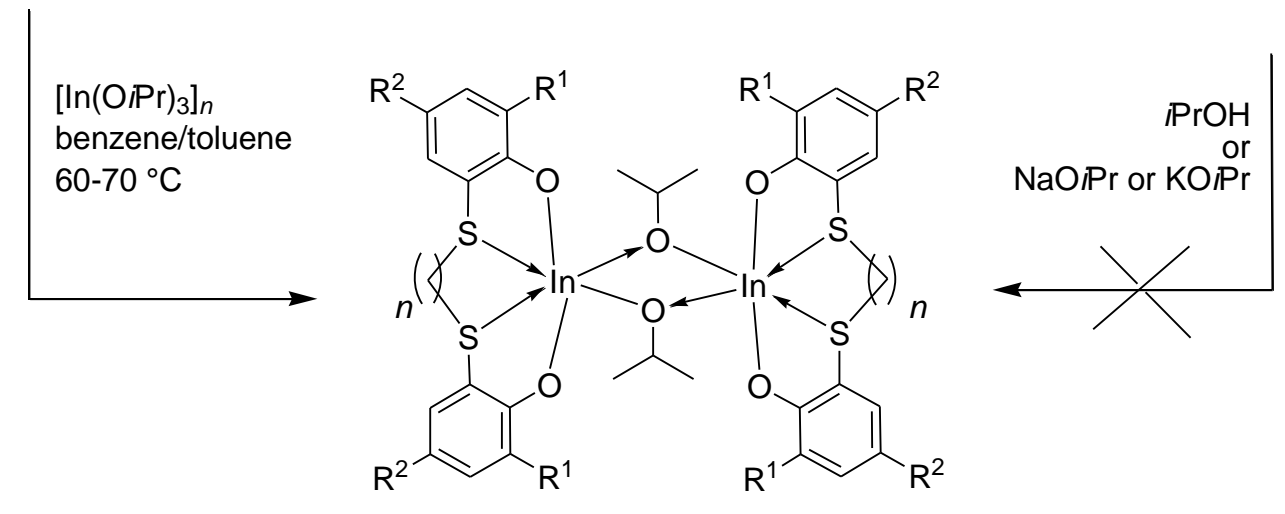

$31 \mathrm{~h}, \mathrm{i}$

Scheme 12. Indium complexes supported by $\{$ OSSO $\}$-type ligands reported by Okuda et al. for the ROP of LA [25].

Quite disappointingly, only few examples of selective salt-metathesis reactions to transform the halo-indium into alkoxy(aryloxy) complexes were reported. Mehrkhodavandi et al. succesfully transformed the chloro-salen indium complex 39 into its corresponding ethoxide derivative 40 (Fig. 7 and 9) by treatment with NaOEt [29]. Diaconescu et al. showed that the expected aryloxy-indium complex 42, supported by a ferrocenyl-based diiminophosphorane-bisphenolate ligand, can be obtained in $85 \%$ yield from the reaction of the corresponding chloro indium complex 41 with sodium phenoxide (Fig. 10) [30]. The other reported attempts to form alkoxy-indium complexes by salt metathesis reactions of chloro 
indium complexes with an alkoxide metal salt resulted in unidentified or undesired products [26,28]. For instance, formation of zwitterionic ate species such as $\mathbf{4 3}$ was documented [26]. Other effective synthetic routes to access discrete indium alkoxide species of potential value as ROP initiators were therefore sought after, primarily protonolysis routes.

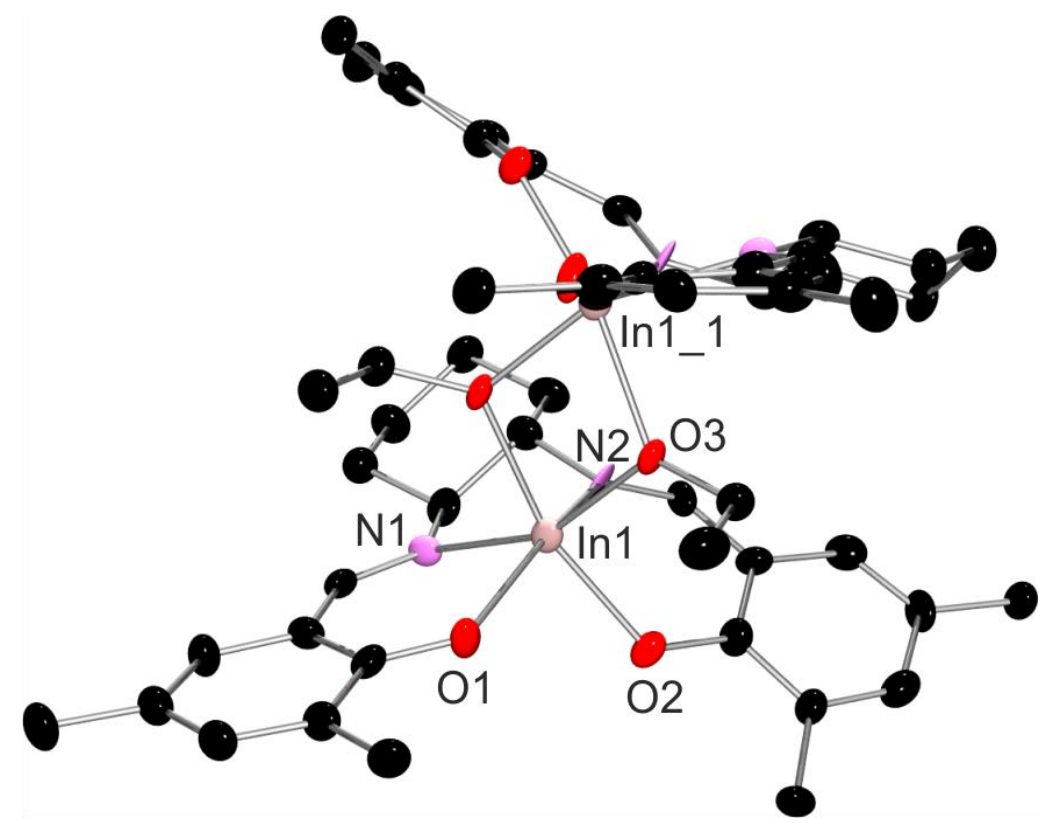

Fig. 9. Molecular structure of the ethoxide complex $\mathbf{4 0}$ (methyls of the $t \mathrm{Bu}$ groups are omitted for clarity) [29].
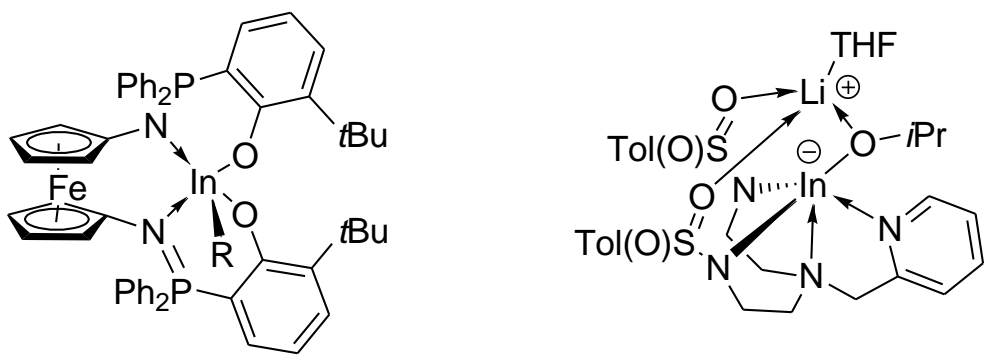

$$
\begin{aligned}
& 41 \mathrm{R}=\mathrm{Cl} \\
& 42 \mathrm{R}=\text { OPh }
\end{aligned}
$$


Fig. 10. Indium complexes supported by a ferrocenyl-diminophosphorane-bisphenoxy ligand [26] and zwitterionic indium derivative [30] obtained upon salt metathesis with an alkoxide.

\subsubsection{Protonolysis reactions}

\subsubsection{Amido complexes}

Protonolysis reactions constitute another route, usually much more selective than salt metathesis reactions, toward well-defined indium complexes. The use of such " $\sigma$-bond metathesis" reactions involved the indium tris(amide) precursor $\operatorname{In}\left[\mathrm{N}\left(\mathrm{SiMe}_{3}\right)_{2}\right]_{3}$ for the preparation of potential catalysts/initiators for ROP reactions and were first described by Arnold, Okuda et al. (Scheme 13) [31]. The reaction of $\operatorname{In}\left[\mathrm{N}\left(\mathrm{SiMe}_{3}\right)_{2}\right]_{3}$ with 2 equiv of the racemic bidentate pro-ligand $(t \mathrm{Bu})_{2} \mathrm{P}(=\mathrm{O}) \mathrm{CH}_{2} \mathrm{CH}(t \mathrm{Bu}) \mathrm{OH}$ proceeded with release of amine, and yielded a diastereomeric mixture composed of $90 \%$ of the racemic amido complex $(R R) /(S S)(45)$ and $10 \%$ of the $(R S)$ diastereomer $\left(\mathbf{4 5}^{\prime}\right)$. When 3 equiv of the protio-ligand were used, a mixture of the homoleptic complex 44 as fac- and mer-isomers and a fivecoordinated indium complex with a pendant non-coordinated $\mathrm{P}=\mathrm{O}$ moiety was obtained. The

presence of these three compounds was established by ${ }^{1} \mathrm{H}$ and ${ }^{31} \mathrm{P}$ NMR spectroscopy, IR analyses and single crystal X-ray diffraction studies for the fac-and mer-isomers (Fig. 11). 


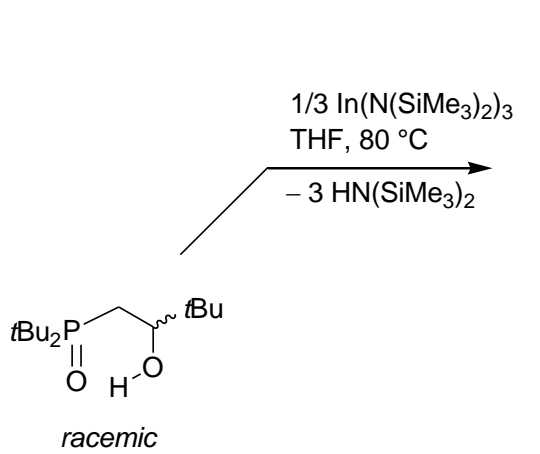

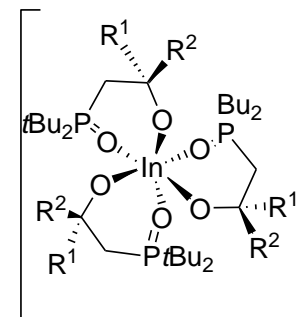

fac-

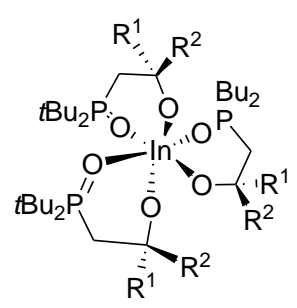

mer-

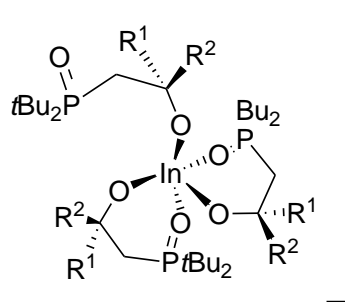

5-coordinate

$44 R_{1}=H, R_{2}=t B u$

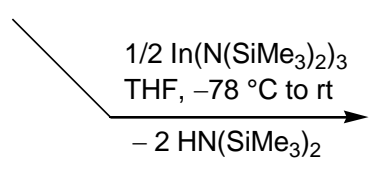

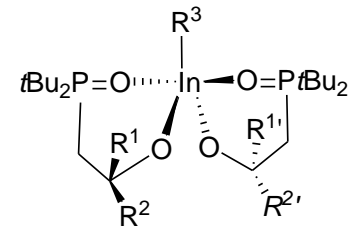

45 rac- $R \boldsymbol{R} / S S \mathrm{R}_{1}=\mathrm{R}_{1}{ }^{\prime}=\mathrm{H}$,

$\mathrm{R}_{2}=\mathrm{R}_{2}{ }^{\prime}=t \mathrm{Bu}$

$\left.\mathrm{R}_{3}=\mathrm{N}(\mathrm{SiMe})_{3}\right)_{2}$

45' meso- $R S \mathrm{R}_{1}=\mathrm{R}_{2}{ }^{\prime}=\mathrm{H}$,

$R_{2}=R_{1}{ }^{\prime}=t B u$

$\left.\mathrm{R}_{3}=\mathrm{N}(\mathrm{SiMe})_{3}\right)_{2}$

\begin{tabular}{l|l}
$-\mathrm{HN}\left(\mathrm{SiMe}_{3}\right)_{2}$ & $\begin{array}{l}2,6-\text { di-tert-butylphenol } \\
\mathrm{C}_{6} \mathrm{D}_{6}, 80^{\circ} \mathrm{C}\end{array}$
\end{tabular}

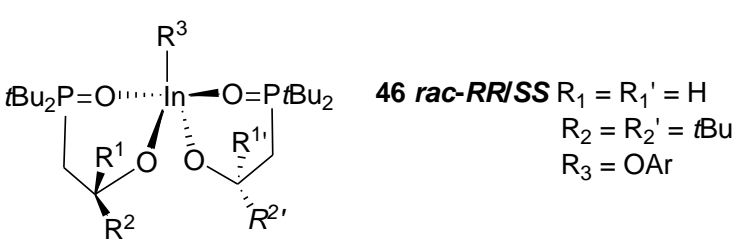

Scheme 13. Five- and six-coordinate indium complexes supported by $\beta$-phosphine oxide alkoxy ligands for ROP of $r a c$-LA [31].
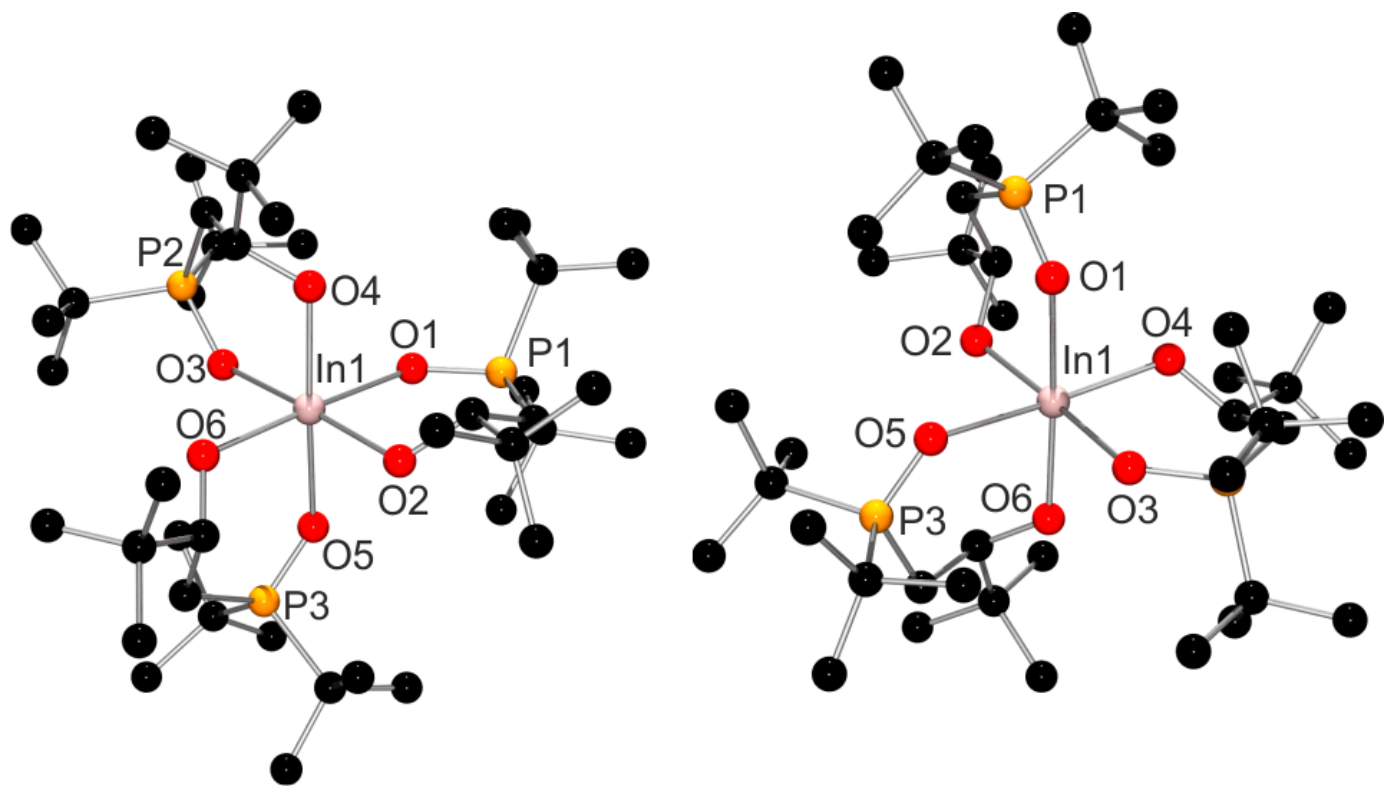
Fig. 11. Molecular structures of the fac- (left) and mer- (right) isomers of 44 [31].

Mountford et al. also described the synthesis of a five-coordinated amido-indium complex bearing a tetradentate triaza ligand (33a, Fig. 7) [26]. The solid state structure features a distorted geometry between trigonal bypyramidal and square pyramidal, with one of the longest $\mathrm{In}-\mathrm{N}\left(\mathrm{SiMe}_{3}\right)_{2}$ bond length $(2.176(3) \AA)$ ever observed for this type of complex (Fig. 12).

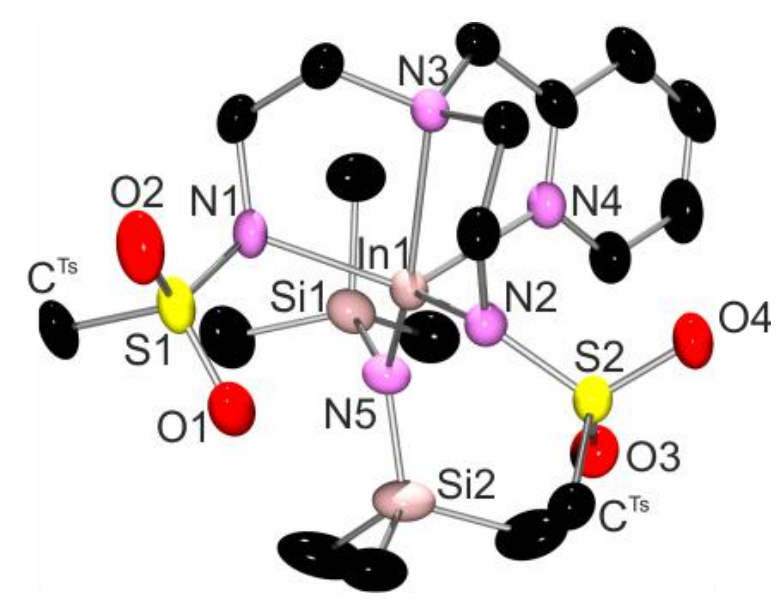

Fig. 12. Molecular structure of complex 33a (para-tolyl moieties of the $t \mathrm{Bu}$ groups are omitted for clarity) [26].

\subsubsection{Alkyl complexes}

$\left[\mathrm{InMe}_{3}\right]_{n}[32]$, which exists as a coordination polymer, has been used as a convenient precursor for the synthesis of mono- and dimethyl-indium derivatives by $\sigma$-bond metathesis approach. This precursor can be used as an isolated product or generated in situ by reacting $\mathrm{InCl}_{3}$ with 3 equiv of $\mathrm{MeLi}$ in polar solvents such as THF and $\mathrm{Et}_{2} \mathrm{O}$. Reactions between $\left[\mathrm{InMe}_{3}\right]_{n}$ and acidic pro-ligands were very selective starting from isolated $\mathrm{InMe}_{3}$. Thus, 
Okuda et al. [25] and Mehrkhodavandi et al. [22] reported the high-yield syntheses of monoand dialkyl-indium complexes 28 (Scheme 12) and 47 (Fig. 13), respectively, starting from isolated $\left[\mathrm{InMe}_{3}\right]_{n}$. Okuda et al. [33] showed that a six-coordinate dinuclear methylindium complex supported by a (1,2-cyclohexanediyldithio)-2,2'-diphenoxy ligand (49, Fig. 13) can be prepared selectively by this approach. On the other hand, when $\left[\mathrm{InMe}_{3}\right]_{\mathrm{n}}$ was generated in situ, a strict 3:1 stoichiometry between $\mathrm{MeLi}$ with $\mathrm{InCl}_{3}$ reagents must be maintained in order to obtain the desired products, although this condition might not be always sufficient. For instance, Mehrkhodavandi et al. observed that the reaction of a diamino-phenol pro-ligand with $\left[\mathrm{InMe}_{3}\right]_{n}$, generated in situ with an insufficient amount of MeLi, led to a mixture of the expected dimethyl-indium derivative 47 contaminated with a bis-indium by-product (48, Fig. 13) [22]. Also, in attempts to synthesize monomethyl-indium complexes of fluorinated dialkoxy ligands $\left(\mathrm{ON}^{R} \mathrm{NO}\right)^{2-}$ by reacting in situ $\left[\mathrm{InMe}_{3}\right]_{n}$ (generated by the strict addition of 3 equiv of $\mathrm{MeLi}$ to $\mathrm{InCl}_{3}$ ), Carpentier et al. reported that bimetallic lithium-indium complexes 38a,b were isolated [28]. The latter observation was rationalized on the basis of a dynamic equilibrium between homoleptic $\left[\mathrm{InMe}_{3}\right]_{n}$ and ate $\mathrm{Li}\left[\mathrm{InMe}_{4}\right]$ complexes, the latter being the kinetic product of the salt metathesis reaction. Also, the successful preparation of dimethyl phenoxy-imine indium complexes 50a,b using in situ generated $\left[\mathrm{InMe}_{3}\right]_{n}$ was achieved only with two pro-ligands; with many other imino-phenol pro-ligands, the reactions were not selective and no pure product could be isolated [34]. 
<smiles></smiles>

47

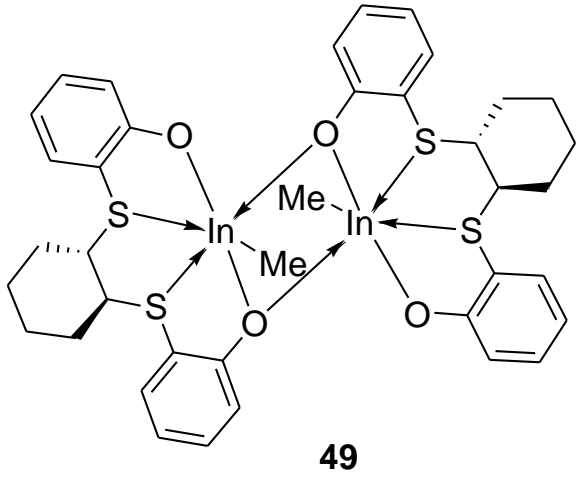

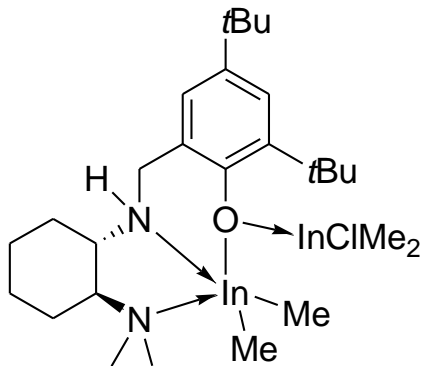

48<smiles></smiles>

50a $R=8$-quinolyl

b $\mathrm{R}=\mathrm{N}$-benzyl-4-piperidinyl

Fig. 13. Dimethyl indium complexes obtained by alkane elimination $[22,34]$.

Compound $\mathrm{In}\left(\mathrm{CH}_{2} \mathrm{SiMe}_{3}\right)_{3}$ is another valuable precursor; it is a stable, liquid product that can be prepared from the Grignard reagent $\mathrm{Me}_{3} \mathrm{SiCH}_{2} \mathrm{MgCl}$ and $\mathrm{InCl}_{3}$ in a $3: 1$ stoichiometry [ 35 ]. $\mathrm{SiMe}_{4}$ elimination reactions between acidic pro-ligands and $\mathrm{In}\left(\mathrm{CH}_{2} \mathrm{SiMe}_{3}\right)_{3}$ proved quite reliable and afforded the corresponding complexes in high yields. For instance, the mono-carbyl four-coordinate complex 32c and five-coordinate complexes 32a,b, 37a, 37b (Fig. 7) and $\mathbf{5 1}$ (Fig. 14) were prepared using this approach [26,28]. Also, a large variety of four- and five-coordinate dicarbyl phenoxy-imine indium complexes of the type $\mathbf{5 0}$ (Fig. 15) were thus prepared, irrespective of the nature of the R imino substituents. ${ }^{34}$ 


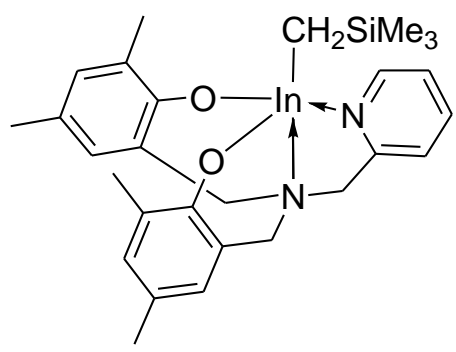

51

Fig. 14. Five-coordinate diamino-bisphenoxy carbyl indium complex used in ROP of cyclic ester [28].
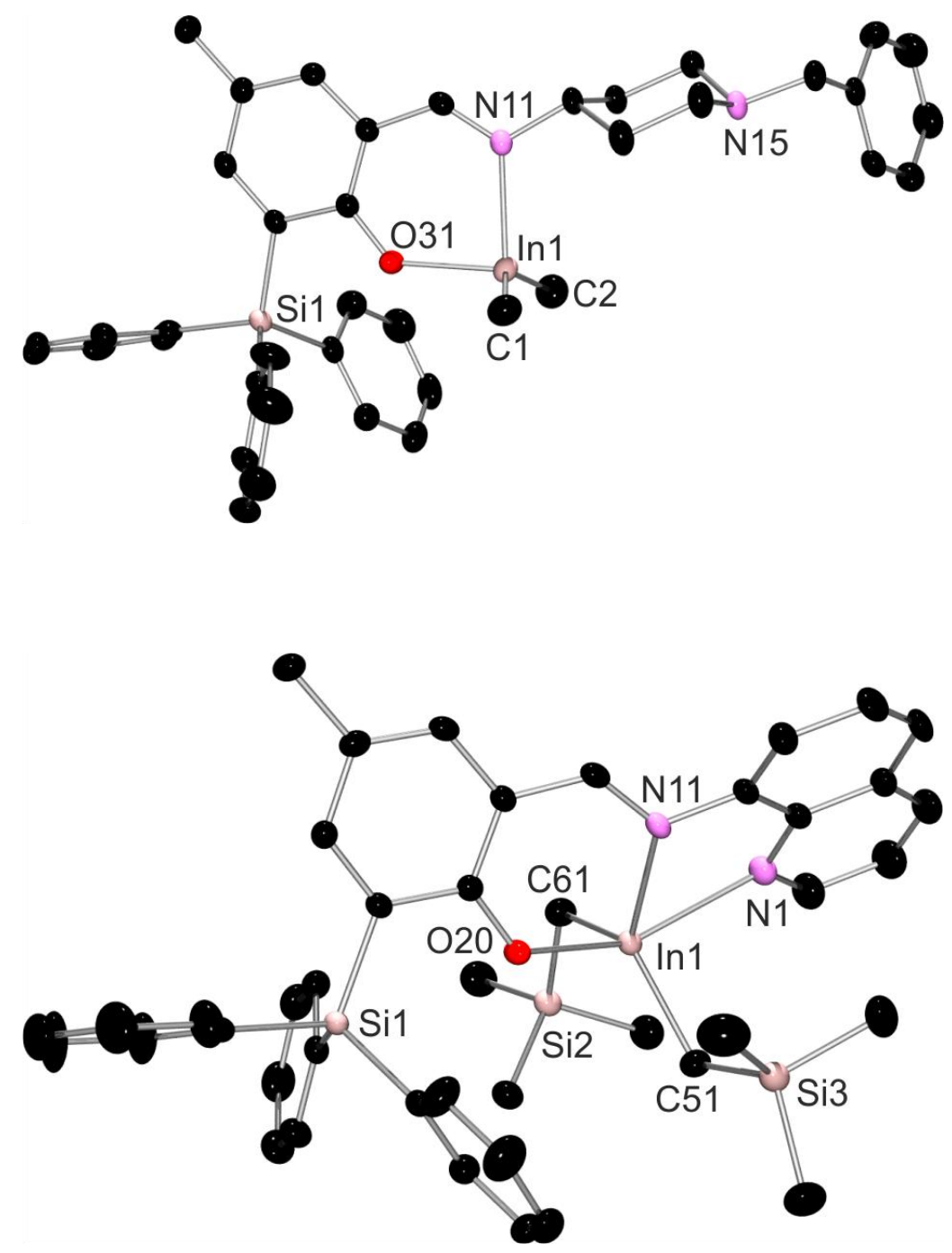

Fig. 15. Molecular structures of four-coordinate (top) and five-coordinate (bottom) dicarbyl phenoxy-imine indium complexes of the type $\mathbf{5 0}$ [34]. 


\subsubsection{Aryloxy and alkoxy complexes}

As abovementioned ( $c f . \S 3.1 .1$.), efforts have been made toward the synthesis of alkoxy-indium complexes, since the latter are assumed to be the actual initiators of the ROP of cyclic esters via coordination-insertion mechanistic pathways (vide infra). Two different protonolysis routes were investigated: i) direct reaction of an acidic pro-ligand with the polymeric tris(alkoxide) precursor $\left[\operatorname{In}(\mathrm{OiPr})_{3}\right]_{n}$, obtained preliminarily by salt metathesis reactions of sodium or potassium isopropoxide salts and an $\operatorname{InX} X_{3}$ precursor [36]; ii) alcoholysis reactions between adequate alkyl- or amido-indium complexes and alcohols.

The sole example of a successful, selective reaction using $\left[\operatorname{In}(\mathrm{O} i \mathrm{Pr})_{3}\right]_{n}$ as precursor was reported by Okuda et al. with dithiabisphenols (Scheme 12) [25]. X-ray crystallographic and variable temperature ${ }^{1} \mathrm{H}$ NMR spectroscopic studies of the resulting compound $\mathbf{3 1 h}$ (Fig. 16) revealed its dimeric structure formed by $\mu$-bridging isopropoxy groups. This species exists in three different isomeric forms $(\Lambda \Lambda, \Delta \Delta$ and $\Lambda \Delta)$ which are stable in toluene and pyridine solutions at ambient temperature. The analogous reaction between $\left[\operatorname{In}(\mathrm{O} i \mathrm{Pr})_{3}\right]_{n}$ and the pro-ligand bearing bulkier cumyl substituents in the ortho- and para-positions of the phenoxy moieties led to the monomeric species in solution, as evidenced by ${ }^{1} \mathrm{H}$ NMR. In other cases, attempts to use the indium precursor $\left[\operatorname{In}(\mathrm{O} i \mathrm{Pr})_{3}\right]_{n}$ led to mixtures of unidentified products $[26,28]$. 


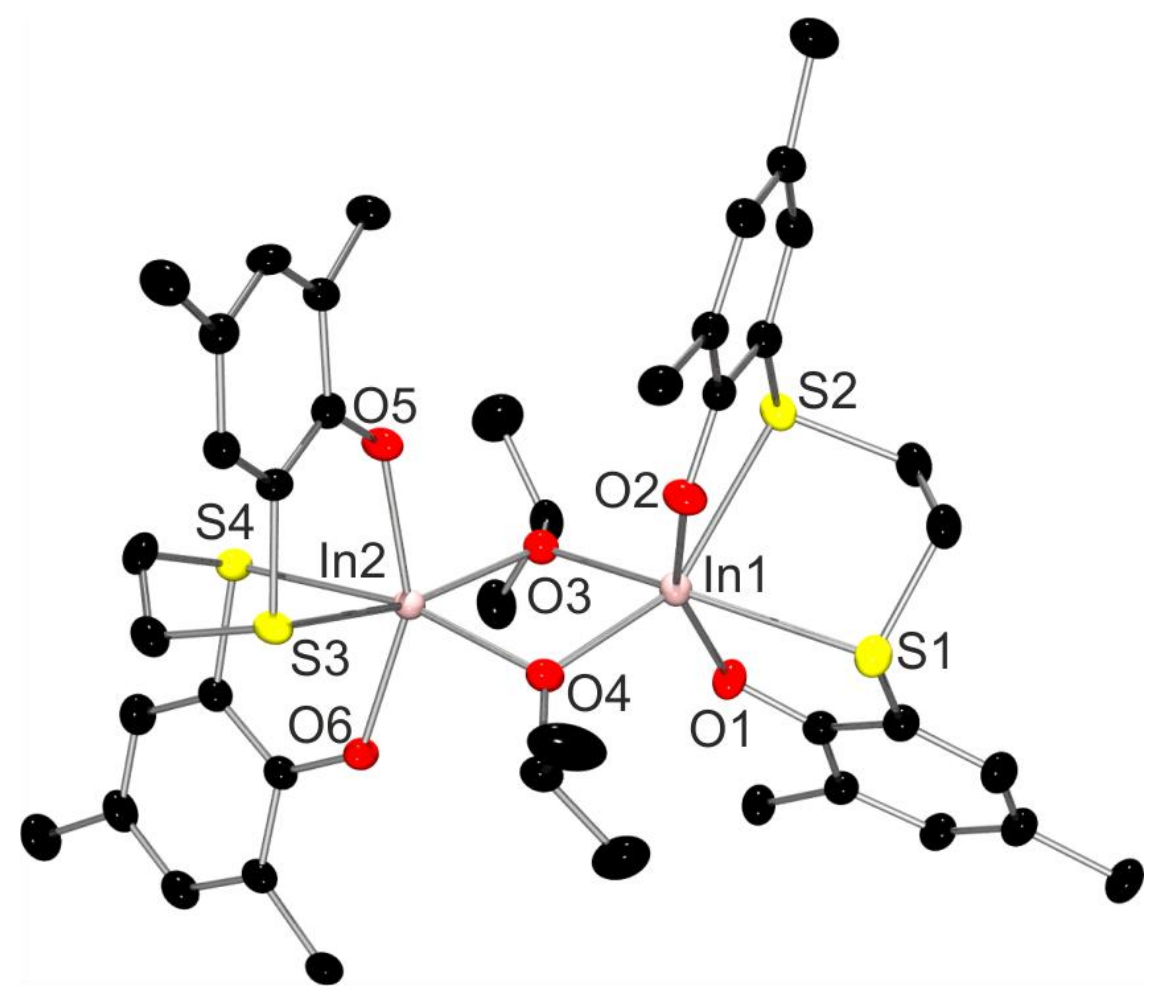

Fig. 16. Molecular structure of compound $31 \mathrm{~h}$ (methyls of the $t \mathrm{Bu}$ groups are omitted for clarity) [25].

Nucleophilic displacement of the $[\mathrm{In}]-\mathrm{N}\left(\mathrm{SiMe}_{3}\right)_{2}$ amido group by 2,6-di-tertbutylphenolate selectively occurred (with $\mathrm{HN}\left(\mathrm{SiMe}_{3}\right)_{2}$ elimination) in the formation of the monomeric aryloxy-indium complex $\mathbf{4 6}$ supported by two equivalent $\beta$-functionalized phosphine oxide-alkoxy ligands (Scheme 13) [31]. On the contrary, treatment of the amido complex 33a (Fig. 7) with $i \mathrm{PrOH}$ resulted in the formation of mixtures of ill-defined products [26]. Interestingly (for mechanistic considerations of the ROP reactions, vide infra), several independent studies reported that dimethyl- (47, Fig. 13) [22] and carbyl-indium (32a,b, 37a,b, 50 and 51, Fig. 7, 13 and 14) [26,28,34] complexes do not undergo protonolysis reaction using a broad range of conditions (polar and non-polar solvents, at room temperature or under reflux, prolonged reaction times). However, the reactions between $\operatorname{In}\left(\mathrm{CH}_{2} \mathrm{SiMe}_{3}\right)_{3}$ and 1 equiv of $\mathrm{ROH}\left(\mathrm{R}=i \mathrm{Pr}, \mathrm{CH}_{2} \mathrm{CH}_{2} \mathrm{NMe}_{2}\right)$ yielded the expected complexes, four- 
coordinate di- $\mu_{2}$-OiPr-bridged $\left[\operatorname{In}\left(\mathrm{CH}_{2} \mathrm{SiMe}_{3}\right)_{2}(\mathrm{O} i \mathrm{Pr})\right]_{2}$ and five-coordinate $\mu_{2}$-dialkoxybridged [ $\left.\mathrm{In}\left(\mathrm{CH}_{2} \mathrm{SiMe}_{3}\right)_{2}\left(\mathrm{OCH}_{2} \mathrm{CH}_{2} \mathrm{NMe}_{2}\right)\right]_{2}$ (Fig. 17), respectively [26].
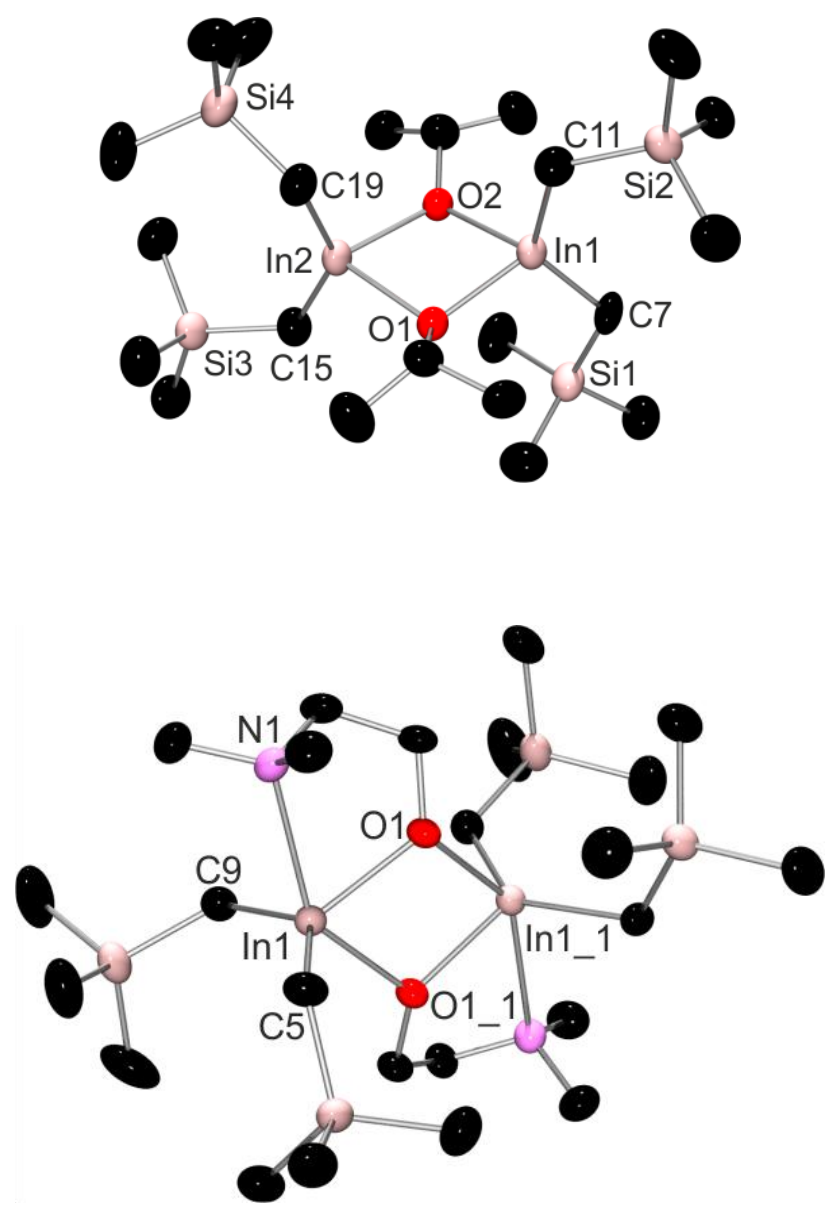

Fig. 17. Molecular structures of four-coordinate (top) and five-coordinate (bottom) $\mu_{2^{-}}$ dialkoxy-bridged complexes of indium [26].

\subsection{Polymerization of cyclic esters using indium complexes}

\subsubsection{Amido-indium precursors}

The racemic mixture of complex $\mathbf{4 5}$ (Scheme 13) was evaluated as an initiator for the ROP of $r a c$-LA in THF and dichloromethane at room temperature ([rac-LA]/[In] $=$ 554-1 108) [31]. A linear relationship between molecular weights $\left(M_{\mathrm{n}}\right)$ and monomer 
conversions, along a quite close agreement between calculated and experimental molecular weights, demonstrated good initiation efficiency and an overall good control over the polymerization. The polymers isolated from experiments quenched at moderate conversions $(<56 \%)$ featured narrow molecular weights distributions $\left(M_{\mathrm{w}} / M_{\mathrm{n}}<1.3\right)$. In dichloromethane, longer reaction times were needed to produce high molecular weight $\left(\mathrm{Me}_{3} \mathrm{Si}\right)_{2} \mathrm{~N}$-terminated PLAs, with somewhat larger polydispersities $\left(M_{\mathrm{w}} / M_{\mathrm{n}}=1.5-2.0\right)$. Under the same conditions, the enantiopure version $(R, R)-\mathbf{4 5}$ polymerized L-LA faster than the racemic version of $\mathbf{4 5}$, along with a better control of the molecular weight distribution $\left(M_{\mathrm{w}} / M_{\mathrm{n}}=1.16 v s .2 .8\right)$; this highlighted the preference of the enantiopure $(R, R)$-initiator for $(S, S)$-LA. Yet, only a moderately heterotactic PLA $\left(P_{\mathrm{r}}=0.61-0.65\right)$ was isolated from the ROP of rac-LA using rac-45.

The ROP of rac-LA (100 equiv vs. In) promoted by complex 33a was studied both in melt $\left(130{ }^{\circ} \mathrm{C}\right)$ and in solution (toluene, $\left.70{ }^{\circ} \mathrm{C}\right)$. The kinetic data in solution indicated a first order on monomer concentration. The plot of the molecular weight $\left(M_{\mathrm{n}}\right)$ vs. monomer conversion featured a linear relationship and the polymers had narrow molecular weight distributions $\left(M_{\mathrm{w}} / M_{\mathrm{n}}<1.20\right)$. However, the experimental molecular weights of polymers were much higher than the expected ones, consistent with only $15-50 \%$ initiation efficiency. In melt conditions, the experimental molecular weights of the PLAs were closer to the expected ones, and a somehow larger distribution $\left(M_{\mathrm{w}} / M_{\mathrm{n}}=1.36\right)$ was observed. No stereoselectivity was induced by this initiator though.

\subsubsection{Alkyl-indium precursors}

The methyl indium complex 14 (Scheme 10) was used for the ROP of CL (toluene, 0-60 ${ }^{\circ} \mathrm{C}, 100$ equiv monomer) [19]. The PCLs exhibited molecular weights up to 70800 g.mol ${ }^{-1}$ and relatively narrow molecular weight distributions $\left(M_{\mathrm{w}} / M_{\mathrm{n}}=1.2-1.6\right)$. No chain- 
end methyl group was identified by ${ }^{1} \mathrm{H}$ NMR spectroscopy and the precise nature of the initiating group could not be determined; formation of cyclic polymers cannot be ruled out in this case.

The ROP of rac-LA mediated by the bimetallic ate-complexes 38a,b (Fig. 7), in toluene at $80{ }^{\circ} \mathrm{C}$, proceeded faster with $\mathbf{3 8 b}$ than with 38a (99\% conversion of 100 equiv of LA after $1 \mathrm{~h}$ vs. 96\% conversion after $18 \mathrm{~h}$, respectively) [28]. Assuming that one polymer chain grew per In center, the experimental molecular weights $\left(M_{\mathrm{n}}\right)$ were close to the expected ones. However, polymers had rather broad distributions $\left(M_{\mathrm{w}} / M_{\mathrm{n}}=2.0-2.6\right)$. The addition of $i \mathrm{PrOH}$ as exogenous co-activator improved significantly the control over molecular weights; yet, the PLA samples still featured large molecular weight distributions $\left(M_{\mathrm{w}} / M_{\mathrm{n}}=1.7-2.4\right)$. All those PLAs showed a very modest bias toward heterotactic enchainments $\left(P_{\mathrm{r}}=0.53-0.62\right)$.

The ROP of L-LA promoted by the monocarbyl indium complex $\mathbf{2 9 h}$ (Scheme 12) (27\% conversion of 100 equiv to PLLA, $4 \mathrm{~h}, 100{ }^{\circ} \mathrm{C}$, toluene) resulted in a polymer with a molecular weight much higher than the calculated one, indicating a very low initiation efficiency for this complex [25].

The two monocarbyl indium species 32a (Fig. 7) and $\mathbf{5 1}$ (Fig. 14), bearing a pyridyl donor group, were active in the ROP of $r a c$-LA $\left(k_{\text {app }}=0.52\right.$ and $0.76 \mathrm{~h}^{-1}$, respectively; toluene, $\left.70{ }^{\circ} \mathrm{C},[\mathrm{LA}] /[\mathrm{In}]=100\right)$ [26]. Switching to the complexes with ether and phenyl moieties (instead of the pyridyl group), 32b and 32c respectively (Fig. 7), dramatically decreased the ROP activity ( $k_{\text {app }}=0.013$ and $0.027 \mathrm{~h}^{-1}$, respectively). Nonetheless, only a small fraction of the complexes initiated the ROP of rac-LA, as evidenced from the observation of experimental molecular weights $\left(M_{\mathrm{n}}\right) c a .3$ times higher than the expected ones. Nevertheless, polymers had narrow distributions $\left(M_{\mathrm{w}} / M_{\mathrm{n}}<1.16\right)$. Of important note, an NMR scale reaction between 32a, $\mathrm{BnNH}_{2}$ and $r a c$-LA indicated the release of the protio-ligand from complex [26]; thus, in ROP reactions carried out under these conditions, the main active species was 
not the expected protonolysis product, but rather the free-ligand itself and/or ill-defined metal species. In controlled experiments, the ROP of rac-LA was assessed using $\operatorname{In}\left(\mathrm{CH}_{2} \mathrm{SiMe}_{3}\right)_{3}$ in combination with 5 equiv of $\mathrm{BnNH}_{2}$ (toluene, $70{ }^{\circ} \mathrm{C}$ ); these reactions actually afforded polymers with experimental molecular weights in good agreement with the calculated ones and featuring narrow distributions $\left(M_{\mathrm{w}} / M_{\mathrm{n}}<1.12\right)$. However, the polymerizations proceeded very slowly at room temperature $\left(k_{\text {app }}<0.015 \mathrm{~h}^{-1}\right)$. NMR monitoring of the reaction between $\mathrm{BnNH}_{2}$ and $\operatorname{In}\left(\mathrm{CH}_{2} \mathrm{SiMe}_{3}\right)_{3}$ showed the formation of $\left[\mathrm{In}\left(\mathrm{CH}_{2} \mathrm{SiMe}_{3}\right)_{2}(\mathrm{NHBn})\right]_{2}$, that is the amido analogue of the previously described isopropoxy-bridged dimer $\left[\mathrm{In}\left(\mathrm{CH}_{2} \mathrm{SiMe}_{3}\right)_{2}(\mathrm{OiPr})\right]_{2}$ [26]. Both these benzylamido and isopropoxy indium derivatives were used to initiate the ROP of rac-LA (toluene, $70{ }^{\circ} \mathrm{C}, 100$ equiv), resulting in atactic benzylaminocarbonyl- and isopropoxycarbonyl- end-capped PLAs, respectively.

Monocarbyl (diimino-dialkoxy)-indium complexes 37a,b (Fig. 7) exhibited low initiation efficiency ( $22 \%$ and $48 \%$, respectively) in the ROP of LA (toluene, $80{ }^{\circ} \mathrm{C}$, [LA]/[In] $=100-500)$, producing polymers with quite variable molecular weight distributions $\left(M_{\mathrm{w}} / M_{\mathrm{n}}=\right.$ 1.21 and 2.0, respectively). Combination of 37a,b with exogenous $i \mathrm{PrOH}$ resulted in a much better control over the polymerization, producing PLAs with narrow distributions $\left(M_{\mathrm{w}} / M_{\mathrm{n}}=\right.$ 1.08-1.21). As already mentioned, independent reactions between complexes 37a,b and $i \mathrm{PrOH}$, carried out under various experimental conditions, demonstrated that these complexes remain reluctant to undergo protonolysis reactions. These data suggest the occurrence of an "activated monomer" mechanism rather than the usually claimed and/or assumed “coordination-insertion" one for the ROP of rac-LA (Scheme 14) [28,37]. In such "activated monomer" mechanism, the metal center acts a Lewis acid which activates, upon coordination, the monomer towards the external attack of a neutral nucleophilic initiator, i.e. the exogenous (macro)alcohol; this contrasts with the "coordination-insertion" mechanism where ringopening proceeds via the nucleophilic reactivity of an inner sphere ligand, i.e. the anionic 
(macro)alkoxide $\sigma$-bonded to the Lewis acidic metal center. The PLAs obtained from complexes 37a,b featured a modest isotactic bias $\left(P_{\mathrm{m}}=0.62-0.69\right)$, contrasting with the high $P_{\mathrm{m}}$ values observed for the polymers obtained with the analogous aluminum derivatives $\left(P_{\mathrm{m}}=\right.$ 0.80-0.87) [38]. The authors tentatively attributed this difference in stereoselectivity to the influence of a larger ionic radius of the indium metal center and/or the apparently different operative mechanism.

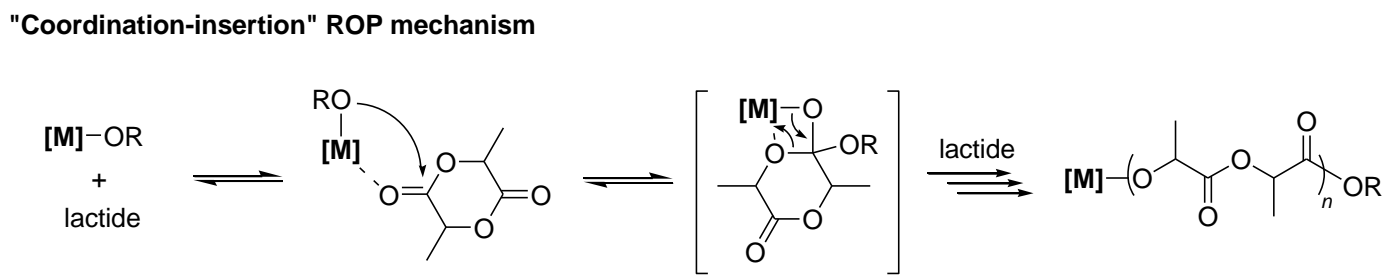

"Activated monomer" ROP mechanism

monomer activation and ring-opening

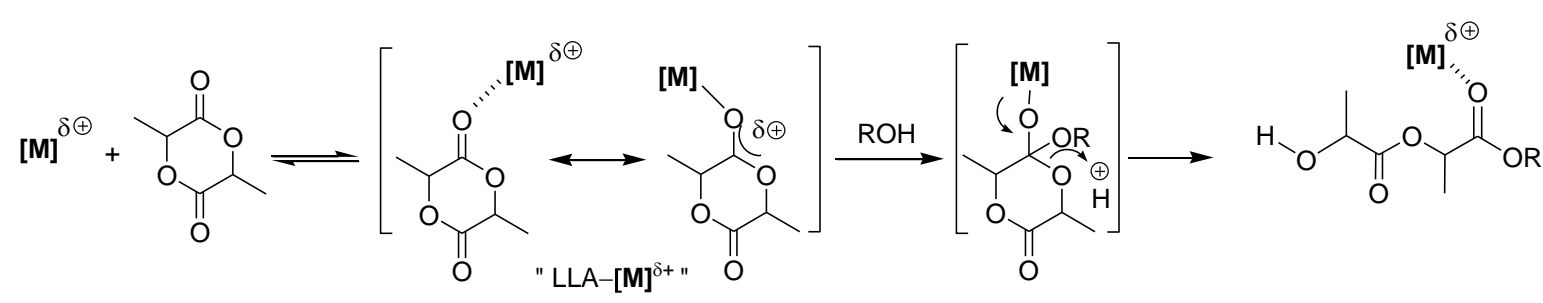

propagation

$[\mathrm{M}]$<smiles>COC(C)C(=O)OC(C)C(=O)OC(C)C</smiles><smiles>CCOC(=O)C(=O)OC(C)C(=O)OC(C)C</smiles>

exchange/transfer reactions

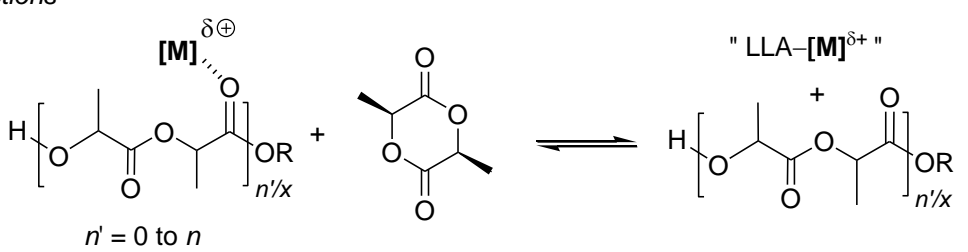

Scheme 14. Representations of the "coordination-insertion" (top) and "activated monomer" (bottom) mechanisms operative in ROP of lactide. 
Phenoxy-imine dialkyl indium complexes $\left\{\mathrm{ON}^{\mathrm{R}}\right\} \mathrm{InR}_{2}{ }_{2}\left(\mathrm{R}^{\prime}=\mathrm{Me}, \mathrm{CH}_{2} \mathrm{SiMe}_{3}\right)$ of the type 50 (Fig. 13 and 15) were investigated in the ROP of rac-LA and compared to their dimethyl aluminium analogues $\left\{\mathrm{ON}^{\mathrm{R}}\right\} \mathrm{AlMe}_{2}[34]$. When combined with an alcohol $(i \mathrm{PrOH}$ or $\mathrm{BnOH}$; up to 10 equiv vs. In), the $\left\{\mathrm{ON}^{\mathrm{R}}\right\} \mathrm{InR}_{2}{ }_{2}$ complexes promoted the living immortal polymerization $((i) \mathrm{ROP})$ of $r a c$-LA $\left(\mathrm{TOF}=c a .40 \mathrm{~mol}(\mathrm{LA}) \cdot \mathrm{mol}(\mathrm{In})^{-1} \cdot \mathrm{h}^{-1}\right.$ at $\left.80{ }^{\circ} \mathrm{C}\right)$ and good control over the molecular weights with narrow polydispersities $\left(M_{\mathrm{w}} / M_{\mathrm{n}}=1.06-1.13\right)$. However, none of the complexes induced stereoselectivity, except that supported by a 8quinolyl phenoxy-imine ligand, $\left\{\mathrm{ONN}^{\text {qui }}\right\} \mathrm{InMe}_{2}$, which produced PLA with a noticeable isotactic bias $\left(P_{\mathrm{m}}=0.70\right)$. The analogous $\left\{\mathrm{ON}^{\mathrm{R}}\right\} \mathrm{AlMe}_{2}$ proved similarly active for the $(i) \mathrm{ROP}$ of rac-LA in presence of an external alcohol, but achieved a significantly better stereocontrol than their indium analogues $\left(P_{\mathrm{m}}\right.$ up to 0.80 for a variety of $\mathrm{Al}$ complexes having benzyl-type imino-substituents). Interestingly, while the indium complexes $\left\{\mathrm{ON}^{\mathrm{R}}\right\} \operatorname{InR}_{2}$, proved largely inert towards alcohols, the $\left\{\mathrm{ON}^{\mathrm{R}}\right\} \mathrm{AlMe}_{2}$ complexes react with alcohols, in particular with alkyl $(S)$-H-lactate, to generate the corresponding $\left\{\mathrm{ON}^{\mathrm{R}}\right\}_{2-\mathrm{n}} \mathrm{Al}(\mathrm{OR})_{\mathrm{n}+1}(n=0,1)$ alkoxy compounds. Based on these differences whether regarding catalytic and stoichiometric behaviors, two different operative ROP mechanisms were suggested, depending on the nature of the metal center: it was thus proposed that Al-based complexes proceed through "coordination-insertion", as evidenced by the activity of isolated $\left\{\mathrm{ON}^{\mathrm{R}}\right\}_{2-\mathrm{n}} \mathrm{Al}(\mathrm{OR})_{\mathrm{n}+1}$ complexes, while In-based complexes operate through an "activated monomer" mechanism (Scheme 14).

\subsubsection{Alkoxy-indium complexes}

a. Discrete monomeric and dimeric alkoxy-indium complexes

The isopropoxy indium complexes 31h,i (Scheme 12) are active initiators for the ROP of L-LA (toluene, $50{ }^{\circ} \mathrm{C}, 100$ equiv converted within $3.3 \mathrm{~h}$ ) [25]. The polymers were 
narrowly dispersed $\left(M_{\mathrm{w}} / M_{\mathrm{n}}=1.03-1.09\right)$ but no linear correlation could be found between experimental molecular weights and monomer conversion. The thermodynamic data measured for these ROP reactions $\left(\mathbf{3 1 h}: \Delta H^{\ddagger}=79(0) \mathrm{kJ} \cdot \mathrm{mol}^{-1}, \Delta S^{\ddagger}=-41(6) \mathrm{J} \cdot \mathrm{K}^{-1} \cdot \mathrm{mol}^{-1} ; \mathbf{3 1 i}\right.$ : $\Delta H^{\ddagger}=62(3) \mathrm{kJ} \cdot \mathrm{mol}^{-1}, \Delta S^{\ddagger}=-89(1) \mathrm{J} \cdot \mathrm{K}^{-1} \cdot \mathrm{mol}^{-1}$ ) are similar to those reported by Mehrkhodavandi et al. [23,24]. As compared to their previously described alkyl aluminum congener in presence of one equiv of $i \mathrm{PrOH},{ }^{39}$ the indium derivatives $\mathbf{3 1 h}, \mathbf{i}$ appeared to be similarly active $\left(\mathrm{TOF}=31 \mathrm{~mol}(\mathrm{LA}) \cdot \mathrm{mol}(\mathrm{Al})^{-1} \cdot \mathrm{h}^{-1}\right.$ at $70{ }^{\circ} \mathrm{C} v \mathrm{~s} .16 \mathrm{~mol}(\mathrm{LA}) \cdot \operatorname{mol}(\mathrm{In})^{-1} \cdot \mathrm{h}^{-1}$ at $50{ }^{\circ} \mathrm{C}$ or $\mathrm{TOF}=30 \mathrm{~mol}(\mathrm{LA}) \cdot \mathrm{mol}(\mathrm{In})^{-1} \cdot \mathrm{h}^{-1}$ at $\left.100{ }^{\circ} \mathrm{C}\right)$. Also, similarly to the aluminum complexes, rac-LA ROP with $\mathbf{3 1 h}, \mathbf{i}$ afforded atactic polymers.

The racemic amido complex 45 and the aryloxy-indium complex 46 (Scheme 13) described by Okuda et al. were evaluated in the ROP of rac-LA (dichloromethane, room temperature, $[\mathrm{LA}] /[\mathrm{In}]=600-2500)$ [31]. MALDI-ToF MS analyses of the resulting PLAs revealed that the polymerization is initiated by the "ancillary" ligand in the case of $\mathbf{4 5}$ and by the aryloxy group using complex 46, as observed for related group 3 analogues [40]. Nonetheless, the linear relationship between molecular weights and conversion, and the relatively narrow molecular weights distributions $\left(M_{\mathrm{w}} / M_{\mathrm{n}}=1.2-1.7\right)$ were indicative of an overall controlled ROP process. Expectedly, the metal-aryloxy group was a less efficient initiating group than the alkoxy one (42\% conversion of 1170 equiv after $16 \mathrm{~h} v$ s. $99 \%$ conversion of 1248 equiv after $16 \mathrm{~h}$ ). The ${ }^{1} \mathrm{H}$ NMR spectroscopic data exhibited a very modest isotactic bias $\left(P_{\mathrm{m}}=0.53-0.63\right)$ for these polymers.

Rac- and (R,R)-salen ethoxide complexes 40 (Fig. 7) described by Mehrkhodavandi et al. are highly active initiators / catalysts for the ROP of rac-LA: 97\% conversion of 200 equiv of monomer proceeded in $30 \mathrm{~min}$ at $25^{\circ} \mathrm{C}$ in $\mathrm{CH}_{2} \mathrm{Cl}_{2}$ [29]. Up to 1000 equiv of $\mathrm{rac}$-LA were converted within $4 \mathrm{~h}$ under these conditions, which compares very favorably with aluminum analogues that typically require operating at higher temperatures. The ROP 
proceeded with good control over the molar masses, with polydispersity values close to 1.5 and, interestingly, a significant bias toward isotacticity $\left(P_{\mathrm{m}}\right.$ up to 0.77$)$ was observed with $(R, R)$-40. A site-stereocontrol mechanism was proposed based on kinetic measurements with rac-, L- and D-lactides.

b. Mono or bis- $\mu_{2}-\mathrm{O}$-bridged halide indium complexes

The water-bridged dinuclear chloro-indium complex 35 (Fig. 7) described by Sun et al. [27] promote the ROP of rac-LA (100 equiv, toluene, reflux), producing low molecular weight PLAs $\left(M_{\mathrm{n}}=3700-5700 \mathrm{~g} \cdot \mathrm{mol}^{-1}\right)$ with rather narrow polydispersities $\left(M_{\mathrm{w}} / M_{\mathrm{n}}=\right.$ 1.22-1.31). The polymerization activity was not affected when the polymerization was carried out in air or under inert gas, or in combination with an exogenous alcohol (BnOH or $\mathrm{EtOH}$ ), or even in the presence of water. This observation questions the identity of the actual active species. The resulting PLAs featured a slight heterotactic bias $\left(P_{\mathrm{r}}=0.63-0.69\right)$.

ROP of LA using dinuclear $\mu_{2}$-halide/ethoxy complexes 19a,c, 21e, 33e and 27e (Scheme 11) developed by Mehrkhodavandi et al. appeared to be living, with a good correlation between experimental $M_{\mathrm{n}}$ values and lactide conversion along with narrow polydispersities for polymers $[20,22,41]$. A run performed at a high [monomer]/[In] ratio of 2100 allowed the production of high molecular weight PLA (up to $350000 \mathrm{~g} \cdot \mathrm{mol}^{-1}$ ), revealing this catalyst as one of the most efficient among indium compounds.

Two possible mechanisms for the ROP of LA promoted by 19a and 23e were proposed (Scheme 15) [24]. The first one is a classical "coordination-insertion" mechanism consisting of two steps: i) dissociation of the dimeric complex in the presence of LA by coordination of the monomer onto the metal center, ii) initiation by the nucleophilic In-OEt group. This mechanism was shown to operate for the $\mu_{2}$-OEt bridged halide indium complexes 19b,c. The second mechanism, still revolving around coordination-insertion, 
involves the formation of dinuclear propagating species derived from the bridged dinuclear $\mu_{2}$-OEt-halide indium initiator $\mathbf{1 9 a}$, in which one polymer chain grows per bridged ethoxide. A comparative study between 19a and 23e disclosed major differences in activity and stereoselectivity. Kinetic data obtained for these dinuclear indium complexes exhibited firstorder dependence on the monomer and catalyst/initiator concentrations, that is an overall rate law expressed as: $-\mathrm{d}[\mathrm{LA}] / \mathrm{d} t=k_{\mathrm{p}}[\mathrm{LA}]$ [catalyst/initiator]. Yet, the dinuclear indium complex 19a was less active that the diethoxy-bridged complex 23e $\left(k_{\mathrm{p}}=0.57\right.$ vs. $1.78 \mathrm{M}^{-1} \cdot \mathrm{s}^{-1}$, respectively). The thermodynamic data for the ROP reactions initiated by these complexes, although different, were relatively close in terms of free energy $\left(\Delta G^{\ddagger}{ }_{273 \mathrm{~K}}=87(2), 70(4)\right.$ $\mathrm{kJ} \cdot \mathrm{mol}^{-1}$ for $19 \mathrm{a}$ and $23 \mathrm{e}$, respectively), suggesting similar transition states in the proposed “coordination-insertion" mechanism.

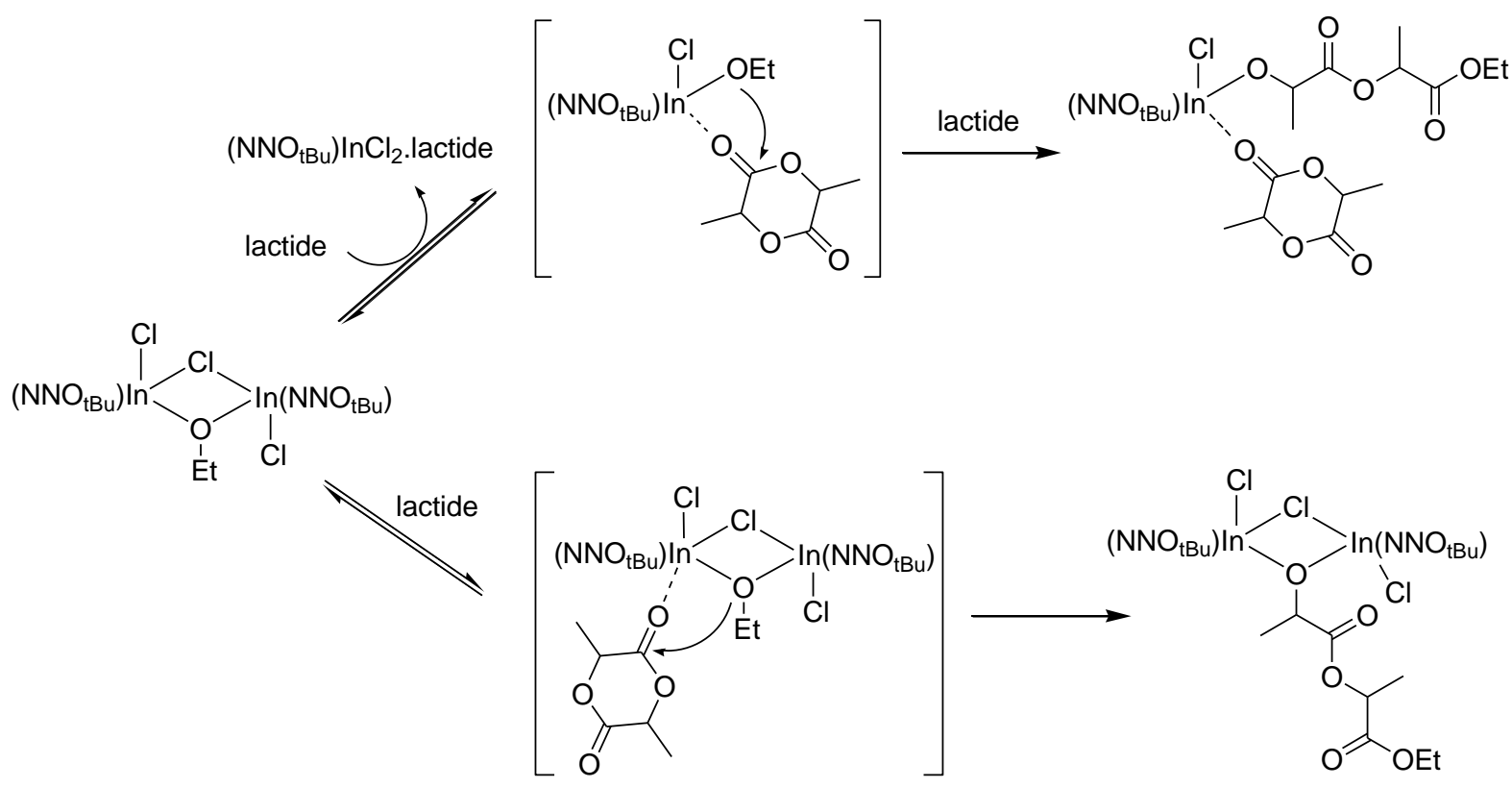

Scheme 15. Mechanistic proposals for ROP of LA mediated by dinuclear halide/ethoxyindium complex type complexes (19a-c) [24]. 
Use of the enantiopure $(R, R / R, R)$ or $(S, S / S, S)$ versions of 19a and 23e brought additional mechanistic clues [22]. The relative rate value $\left(k_{\mathrm{rel}}=k_{\mathrm{L}} / k_{\mathrm{D}}\right)$ in the ROP of L- and DLA using $(R, R / R, R)-19 \mathrm{a}$ as initiator was determined to be of $c a .14$, whereas the reverse value (ca. 1/14) was obtained for $(S, S / S, S)$-19b. These selectivities are not preserved when complex 23e was used. The $k_{\text {rel }}$ value of $c a$. 2 obtained for $(R, R / R, R)$-23e was interpreted as an evidence that a different mechanism is operating in this case. Actually, the authors argued that if an identical dissociative process was operative in both cases, both complexes would have been expected to exhibit the same $k_{\text {rel }}$ values. Besides, dissociation of complex $23 \mathbf{e}$ in presence of LA or polar solvents was observed by ${ }^{1} \mathrm{H}$ NMR spectroscopy, contrary to complex 19a which remained intact. Furthermore, PLA samples obtained with 19a as a catalyst/initiator had a slight isotactic bias $\left(P_{\mathrm{m}}=0.53-0.62\right)$, whereas the PLAs obtained using 23e were atactic. These observations constituted solid clues for the occurrence of two different mechanisms despite the close structural similarity of these two complexes.

The immortal ROP of rac- $\beta$-butyrolactone (rac-BBL), presumed to occur via a coordination-insertion mechanism, was conducted using 19a $([\mathrm{BBL}] /[\mathrm{In}]=200-5000)$ in combination with 2 to 100 equiv of an exogenous alcohol (EtOH or $\left.\mathrm{CH}_{3}\left(\mathrm{OCH}_{2} \mathrm{CH}_{2}\right)_{7} \mathrm{OH}\right)$ [42]. After $21 \mathrm{~h}$ in THF at room temperature, poly(3-hydroxybutyrate)s (PHBs) with high molecular weights (up to $\left.314700 \mathrm{~g} \cdot \mathrm{mol}^{-1}\right)$ and narrow polydispersity $\left(M_{\mathrm{w}} / M_{\mathrm{n}}=1.02-1.07\right)$ were isolated. ROP experiments performed under immortal conditions (i.e., with excess exogenous alcohol) led to highly controlled molecular masses and very narrow molecular weight distributions $\left(M_{\mathrm{w}} / M_{\mathrm{n}}=1.02-1.03\right)$. All PHBs polymers were atactic.

\subsubsection{Three-component initiating systems}

The use of three-component catalytic/initiating systems made of $\mathrm{InCl}_{3}, \mathrm{BnOH}$ and $\mathrm{NEt}_{3}$ for the ROP of $r a c$-LA was first described in 2009 by Tolman, Hillmyer et al. (Scheme 
16) [43]. They demonstrated that the absence of one of these components on the initiation stage did not result in the formation of active ROP species. $\mathrm{NEt}_{3}$ may be replaced by $\mathrm{NBu}_{3}$, $\mathrm{NHBu}_{2}$ or 1,8-bis(dimehtylamino)naphthalene without any detrimental effect on the polymerization control. The latter result suggested that the base is not an integral part of the catalytically active species and is only used to activate the alcohol. The $\left[\mathrm{InCl}_{3}\right] /[\mathrm{BnOH}]$ ratio can be varied from 1:1 to 1:4, still keeping good molecular weight control and narrow polydispersity indices. A zero-order dependence was determined on $\mathrm{NEt}_{3}$ and $\mathrm{BnOH}$ concentrations, while the reaction rates were first-order dependent on $\mathrm{InCl}_{3}$ and $r a c$-LA concentrations ( $k_{\mathrm{obs}}=2.710^{-4} \mathrm{~s}^{-1}$, at $25^{\circ} \mathrm{C}$ in dichloromethane) [44]. The overall rate law was then described as: $-\mathrm{d}[\mathrm{LA}] / \mathrm{d} t=k_{\mathrm{p}}[\mathrm{rac}-\mathrm{LA}]\left[\mathrm{InCl}_{3}\right]$, with $k_{\mathrm{p}}=0.3 \mathrm{M}^{-1} \cdot \mathrm{s}^{-1}$. Most interestingly, the nature of the metal precursor (i.e., $\mathrm{InCl}_{3}$ ) is of particular importance for the ROP process. In fact, analogous systems incorporating $\mathrm{AlCl}_{3}$ or $\mathrm{GaCl}_{3}$ were inactive under similar conditions. An excess of $\mathrm{InCl}_{3}$ vs. $\mathrm{BnOH}\left(\left[\mathrm{InCl}_{3}\right] /[\mathrm{BnOH}]>1\right)$ was observed to slow down the ROP process and the resulting polymers featured broadened molecular weight distributions. Other indium halides, such as $\mathrm{InBr}_{3}$ and $\mathrm{InI}_{3}$, were also tested for the ROP of $r a c$-LA, but only afforded poorly active systems: $k_{\mathrm{obs}}$ for $\mathrm{InBr}_{3}$ was determined of $2.610^{-5} \mathrm{~s}^{-1}$, whereas polymerization using $\mathrm{InI}_{3}$ was mostly ineffective. Quite uniquely, the $\left[\mathrm{NEt}_{3}\right] /[\mathrm{BnOH}] /\left[\mathrm{InCl}_{3}\right](2: 1: 1)$ system formed atactic PLA from meso-LA, while highly heterotactic PLA was obtained from rac-LA $\left(P_{\mathrm{r}}=0.86-0.97\right)$. The first order dependence on L-LA concentration and the respective apparent rate constants for L-LA and $r a c-\mathrm{LA}\left(k_{\mathrm{obs}}{ }^{\mathrm{L}-\mathrm{LA}}=\right.$ $2.110^{-5} \mathrm{~s}^{-1}$ vs. $k_{\mathrm{obs}}{ }^{r a c-\mathrm{LA}}=2.710^{-4} \mathrm{~s}^{-1}$ ) were consistent with the preferred heterotactic alternating incorporation of the monomer. The tacticity was also dependent on the temperature of polymerization. Thus, experiments conducted at lower temperatures resulted in higher heterotacticity values $\left(P_{\mathrm{r}}=0.94\right.$ at $0{ }^{\circ} \mathrm{C} v s . P_{\mathrm{r}}=0.86$ at $60{ }^{\circ} \mathrm{C}$ and $P_{\mathrm{r}}=0.60$ at $\left.140{ }^{\circ} \mathrm{C}\right)$. 

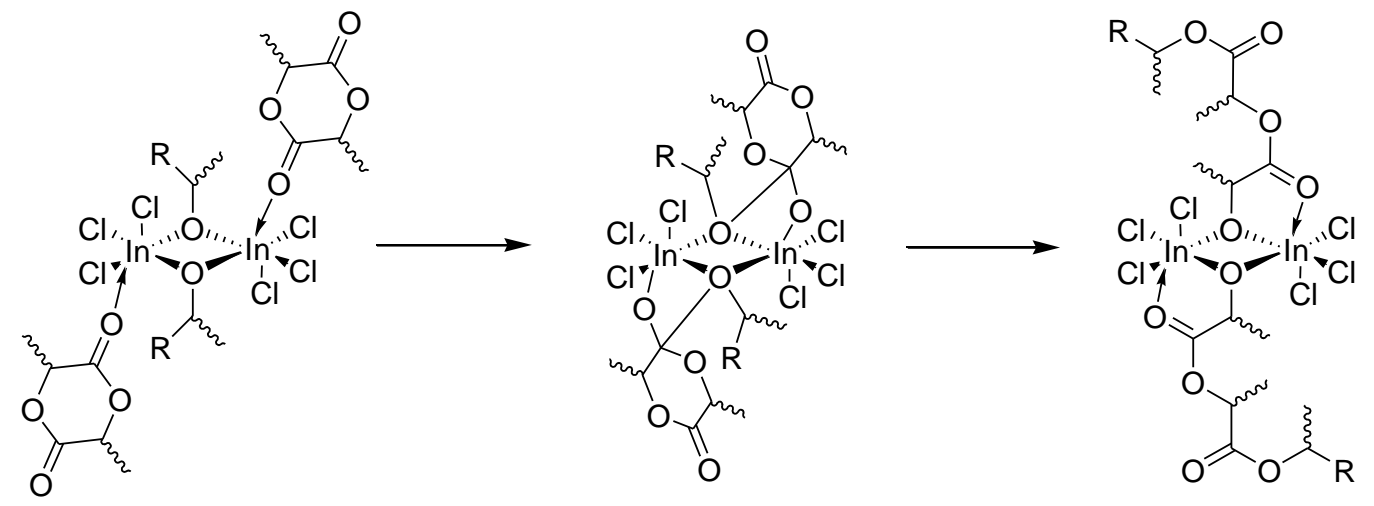

Scheme 16. Proposed mechanism for the ROP of lactide using Tolman-Hillymer's threecomponent system [44].

Structural studies on the isolated model compound $\left[\operatorname{InCl}_{3}(\text { deapH })\left(\mathrm{H}_{2} \mathrm{O}\right)\right]_{2}(\operatorname{deapH}=$ 3-diethylamino-1-propanol; Fig. 18) provided insights in the nature of the active species generated in the polymerization process [44]. Similar structures in solution with various levels of aggregation (between $\left[\mathrm{InCl}_{3}(\operatorname{deapH})\left(\mathrm{H}_{2} \mathrm{O}\right)\right]_{2}$ and $\left[\mathrm{InCl}_{3}(\mathrm{deapH})\right]_{n}$ ) were corroborated by PGSE NMR spectroscopy experiments. The model complex $\left[\operatorname{InCl}_{3}(\operatorname{deapH})\left(\mathrm{H}_{2} \mathrm{O}\right)\right]_{2}$ polymerized $r a c$-LA (though with a lower polymerization rate than the in situ 3-component system: $t_{1 / 2}=155$ vs. 43 min $)$ to yield PLA also with a high heterotactic bias $\left(P_{\mathrm{r}}=0.92\right)$. This is consistent with similar, or at least closely related, active species for $\left[\mathrm{InCl}_{3}(\mathrm{deapH})\left(\mathrm{H}_{2} \mathrm{O}\right)\right]_{2}$ and the system $\left[\mathrm{NEt}_{3}\right] /[\mathrm{BnOH}] /\left[\mathrm{InCl}_{3}\right] \quad(2: 1: 1)$. To further study the polymerization mechanism, the homoleptic indium complex $\left[\mathrm{In}\left(\mathrm{OCH}_{2} \mathrm{CH}_{2} \mathrm{OCH}_{3}\right)_{3}\right]$ was also tested in the ROP of rac-LA, which resulted in atactic PLA. Yet, the addition of $\mathrm{InCl}_{3}$ (1 equiv vs. [ $\left.\left.\mathrm{In}\left(\mathrm{OCH}_{2} \mathrm{CH}_{2} \mathrm{OCH}_{3}\right)_{3}\right]\right)$ led to the production of PLA exhibiting a high heterotacticity $\left(P_{\mathrm{r}}=\right.$ 0.91), implying that the presence of chloride is essential during the polymerization process $[43,44]$. 
Fig. 18. Representation of $\left[\mathrm{InCl}_{3}(\mathrm{deapH})\left(\mathrm{H}_{2} \mathrm{O}\right)\right]_{2}$ based on the X-ray crystal structure [44].

ROP of $\mathrm{CL}$ mediated by the same system ([NEt 3$\left.] /[\mathrm{BnOH}] /\left[\mathrm{InCl}_{3}\right]\right)$ led to the controlled formation of PCL [44]. CL derivatives having methyl-substituents at the 3-, 4- and 5-positions were also used as monomers. The resulting polymers exhibited controlled molecular weights and relatively narrow molecular weight distributions $\left(M_{\mathrm{w}} / M_{\mathrm{n}}=1.05-1.8\right)$.

A similar ternary initiating system, $\mathrm{NEt}_{3} / \mathrm{BnNH}_{2} / \mathrm{InCl}_{3}$ (2:2:1-2:5:1), incorporating benzylamine (instead of benzyl alcohol) was explored by Mountford et al. in the ROP of racLA [26]. This system appeared to be less active by one order of magnitude than that of Tolman and Hillmyer, but performs better than the one generated from $\operatorname{In}\left(\mathrm{CH}_{2} \mathrm{SiMe}_{3}\right)_{3}$ and $\mathrm{BnNH}_{2}$ (vide supra). The polymerization reactions also afforded heterotactic-enriched amineterminated PLAs ( $P_{\mathrm{r}}$ up to 0.85$)$.

\section{Conclusions}

This review gathered a series of results about the behavior of new gallium- and indium-based ROP initiators/catalysts brought into comparison with their aluminum analogues. Some of these species have shown promising potential as catalysts, being equal or even superior to their aluminum counterparts. One of the remaining issues associated with this 
field of chemistry lies in the identification, in each specific case, of the effective polymerization mechanism. Although many of these Ga and In compounds have been claimed to mediate the ROP of cyclic esters via classical "coordination-insertion" pathways (usually more stereoselective), recent investigations have shed light on alternative and plausible “activated monomer" (often less or non- stereoselective) mechanisms. Gaining knowledge on the role of the group 13 metal when combined with the appropriate ligand into promoting a given mechanism would undoubtedly be beneficial to new and yet-be-designed potent stereoselective catalysts for controlled ROP of cyclic esters.

\section{Acknowledgments}

Financial support of this work by the French Ministère de l'Enseignement Supérieur et de la Recherche (PhD grant to $\mathrm{MN}$ ), the Centre National de la Recherche Scientifique, the Université de Strasbourg, and the Université de Rennes 1 is gratefully acknowledged.

\section{References}

[1] (a) B.J. O’Keefe, M.A. Hillmeyer, W.B. Tolman, J. Chem. Soc., Dalton Trans. (2001) 2215

(b) O. Dechy-Cabaret, B. Martin-Vaca, D. Bourissou, Chem. Rev. 104 (2004) 6147;

(c) J. Wu, T.-L. Yu, C.-T. Chen, C.-C. Lin, Coord. Chem. Rev. 205 (2006) 602;

(d) A.P. Dove, Chem. Commun. (2008) 6446;

(e) R.H. Platel, L.M. Hodgson, C.K. Williams, Polym. Rev. 48 (2008) 11;

(f) C.A. Wheaton, P.G. Hayes, B.J. Ireland, Dalton Trans (2009) 4832;

(g) C.M. Thomas, Chem. Soc. Rev. 39 (2010) 165;

(h) A. Arbaoui, C. Redshaw, Polym. Chem. 1 (2010) 801; 
(i) M.K. Kiesewetter, E.J. Shin, J.L. Hedrick, R.M. Waymouth, Macromolecules 43 (2010) 2093;

(j) J.-C. Buffet, J. Okuda, Polym. Chem. 2 (2011) 2758;

(k) P.J. Dijkstra, H. Du, J. Feijen, Polym. Chem. 2 (2011) 520;

(1) S. Dutta, W.-C. Hung, B.-H. Huang, C.-C. Lin, Adv. Polym. Sci., 245 (2012) 219.

[2] (a) M.S. Lindblad, Y. Liu, A.-C. Albertsson, E. Ranucci, S. Karlsson, Adv. Polym. Sci. 157 (2002) 139;

(b) M. Vert, Biomacromolecules 6 (2005) 538;

(c) L.S. Nair, C.T. Laurencin, Prog. Polym. Sci. 32 (2007) 762.

[3] S. Dagorne, C. Fliedel, in: S.W. Woodward, S. Dagorne (Eds.), Modern Organoaluminum Reagents: Preparation, Structure, Reactivity and Use, Topics Organomet. Chem. 41 (2013), Springer, in press.

[4] (a) A. Le Borgne, V. Vincens, M. Jouglard, N. Spassky, Makromol. Chem., Macromol. Symp. 73 (1993) 37;

(b) N. Spassky, M. Wisniewski, C. Pluta, A. Le Borgne, Macromol. Chem. Phys. 197 (1996) 2627;

(c) T.M. Ovitt, G.W. Coates, J. Am. Chem. Soc. 121 (1999) 4072;

(d) C.P. Radano, G.L. Baker, M.R. Smith III, J. Am. Chem. Soc. 122 (2000) 1552;

(e) N. Nomura, R. Ishii, M. Akakura, K. Aoi, J. Am. Chem. Soc. 124 (2002) 5938;

(f) Z. Zhong, P.J. Dijkstra, J. Feijen, J. Am. Chem. Soc. 125 (2003) 11291;

(g) N. Nomura, A. Akita, R. Ishii, M. Mizuno, J. Am. Chem. Soc. 132 (2010) 1750.

[5] S. Dagorne, S. Bellemin-Laponnaz, in: S. Aldridge, A.J. Downs (Eds.), The Group 13 Metals Aluminium, Gallium, Indium and Thallium: Chemical patterns and Peculiarities, Wiley, UK, 2011, pp. 654-700. 
[6] G.A. Olah, O. Farooq, C.X. Li, M.A.M. Farnia, J.J. Aklonis, J. Applied Polym. Sci. 45 (1992) 1355.

[7] M.-A. Munoz-Hernandez, M.L. McKee, T.S. Keizer, B.C. Yearwood, D.A. Atwood, J. Chem. Soc., Dalton Trans. (2002) 410.

[8] G. Linti, A. Seifert, Z. Anorg. Allg. Chem. 634 (2008) 1312.

[9] O.T. Beachley Jr., J.R. Gardinier, M.R. Churchill, Organometallics 22 (2003) 1145.

[10] N. Emig, H. Nguyen, H. Krautscheid, R. Réau, J.-B. Cazaux, G. Bertrand, Organometallics 17 (1998) 3599.

[11] M.H. Chisholm, D. Navarro-Llobet, J. Gallucci, Inorg. Chem. 40 (2001) 6506.

[12] R.J. Wehmschulte, J.M. Steele, J.D. Young, M.A. Khan, J. Am. Soc. Chem. 125 (2003) 1470.

[13] S. Dagorne, S. Bellemin-Laponnaz, A. Maisse-François, M.-N. Rager, L. Jugé, R. Welter, Eur. J. Inorg. Chem. (2005) 4206.

[14] D.J. Darensbourg, D.R. Billodeaux, C. R. Chimie 7 (2004) 755.

[15] D.A. Atwood, M.J. Harvey, Chem. Rev. 101 (2001) 37.

[16] P. Horeglad, P. Kruk, J. Pécaut, Organometallics 29 (2010) 3729.

[17] P. Horeglad, G. Szczepaniak, M. Dranka, J. Zachara, Chem. Commun. 48 (2012) 1171.

[18] F. Hild, N. Neehaul, F. Bier, M. Wirsum, C. Gourlaouen, S. Dagorne, Organometallics, $32(2013) 587$.

[19] I.P. Hsieh, C.-H. Huang, H.M. Lee, P.-C. Kuo, J.-H. Huang, H.-I. Lee, J.-T. Cheng, G.-H. Lee, Inorg. Chim. Acta 359 (2006) 497.

[20] A.F. Douglas, B.O. Patrick, P. Mehrkhodavandi, Angew. Chem. Int. Ed. 47 (2008) 2290.

[21] C.K. Williams, S.K. Breyfogle, S.K. Choi, W. Nam, V.G. Young, M.A. Hillmyer, W.B. Tolman, J. Am. Chem. Soc. 125 (2003) 11350. 
[22] A. Acosta-Ramírez, A.F. Douglas, I. Yu, B.O. Patrick, P.L. Diaconescu, P. Mehrkhodavandi, Inorg. Chem. 49 (2010) 5444.

[23] K.M. Osten, I. Yu, I.R. Duffy, P.O. Lagaditis, J.C.C. Yu, C.J. Wallis, P. Mehrkhodavandi, Dalton Trans. 41 (2012) 8123.

[24] I. Yu, A. Acosta-Ramirez, P. Mehrkhodavandi, J. Am. Chem. Soc. 134 (2012) 12758.

[25] I. Peckermann, A. Kapelski, T.P. Spaniol, J. Okuda, Inorg. Chem. 48 (2009) 5526.

[26] M.P. Blake, A.D. Schwarz, P. Mountford, Organometallics 30 (2011) 1202.

[27] M. Hu, M. Wang, P. Zhang, L. Wang, F. Zhu, L. Sun, Inorg. Chem. Commun. 13 (2010) 968.

[28] M. Normand, E. Kirillov, T. Roisnel, J.-F. Carpentier, Organometallics 31 (2011) 1448.

[29] D. C. Aluthge, B. O. Patrick, P. Mehrkhodavandi, Chem. Commun. (2013) in press; DOI: $10.1039 / \mathrm{C} 2 \mathrm{CC} 33519 \mathrm{~K}$.

[30] E.M. Broderick, N. Guo, C.S. Vogel, C. Xu, J.R. Sutter, J.T. Miller, K. Meyer, P. Mehrkhodavandi, P.L. Diaconescu, J. Am. Chem. Soc. 133 (2011) 9278.

[31] J.-C. Buffet, J. Okuda, P.L. Arnold, Inorg. Chem. 49 (2010) 419.

[32] F. Runge, W. Zimmermann, H. Pfeiffer, I. Pfeiffer, Z. Anorg. Allg. Chem. 267 (1952) 39.

[33] I. Peckermann, T.S. Dols, T.P. Spaniol, J. Okuda, J. Organomet. Chem. 695 (2010) 2325.

[34] M. Normand, V. Dorcet, E. Kirillov, J.-F. Carpentier, submitted.

[35] (a) J.P. Kopasz, R.B. Hallock, O.T. Beachley, Inorg. Synth. 24 (1986) 89;

(b) O.T. Beachley, D.J. MacRae, M.R. Churchill, A.Y. Kovalevsky, E.S. Robirds, Organometallics 22 (2003) 3991; 
(c) I. Peckermann, D. Robert, U. Englert, T.P. Spaniol, J. Okuda, Organometallics 27 (2008) 4817;

(d) I. Peckermann, A. Kapelsky, T.P. Spaniol, J. Okuda, Inorg. Chem. 48 (2009) 5526.

[36] (a) A. Mehrotra, R.C. Mehrotra, Inorg. Chem. 11 (1972) 2170;

(b) S. Chatterjee, S.R. Bindal, R.C. Mehrotra, J. Ind. Chem. Soc. 53 (1976) 867;

(c) D.C. Bradley, H. Chudzynska, D.M. Frigo, M.E. Hammond, M.B. Hursthouse, M.A. Mazid, Polyhedron 9 (1990) 719;

(d) B. Neumüller, M.M. Heravi, N.N. Chamazi, Z. Anorg. Chem. 632 (2006) 2043.

[37] T. Endo, in: Handbook of Ring-Opening Polymerization, P. Dubois, O. Coulembier, J.-M. Raquez (Eds.), Wiley-VCH Verlag GmbH \& Co. KGaA, Weinheim, 2009, pp 53-64.

[38] M. Bouyahyi, T. Roisnel, J.-F. Carpentier, Organometallics 31 (2012) 1458.

[39] M.H. Melillo, G. Oliva, T.P. Spaniol, L. Englert, J. Okuda, Dalton Trans. (2005) 721.

[40] P.L. Arnold, J.-C. Buffet, R.P. Blaudeck, S. Sujecki, A.J. Blake, C. Wilson, Angew. Chem. Int. Ed. 47 (2008) 6033.

[41] For use of these catalysts systems in the preparation of stereoblock polylactides, see also: N. Othman, C. Xu, P. Mehrkhodavandi, S. G. Hatzikiriakos, Polymer 53 (2012) 2443.

[42] C. Xu, I. Yu, P. Mehrkhodavandi, Chem. Commun. 48 (2012) 6806.

[43] A. Pietrangelo, M.A. Hillmyer, W.B. Tolman, Chem. Commun. (2009) 2736.

[44] A. Pietrangelo, S.C. Knight, A.K. Gupta, L.J. Yao, M.A. Hillmyer, W.B. Tolman, J. Am. Chem. Soc. 132 (2010) 11649. 